\title{
REVIEW
}

\section{Early-onset dementias: diagnostic and etiological considerations}

\author{
Mario Masellis*1,2,3,4, Kayla Sherborn, ${ }^{1,2}$, Pedro Rosa Neto ${ }^{5,6,7}$, Dessa A Sadovnick ${ }^{8,9}$, Ging-Yuek R Hsiung ${ }^{8}$, \\ Sandra E Black ${ }^{1,310}$, Sadhana Prasad"1 ${ }^{11}$ Meghan Williams ${ }^{7}$ and Serge Gauthier*5
}

\begin{abstract}
This paper summarizes the body of literature about early-onset dementia (EOD) that led to recommendations from the Fourth Canadian Consensus Conference on the Diagnosis and Treatment of Dementia. A broader differential diagnosis is required for EOD compared with late-onset dementia. Delays in diagnosis are common, and the social impact of EOD requires special care teams. The etiologies underlying EOD syndromes should take into account family history and comorbid diseases, such as cerebrovascular risk factors, that may influence the clinical presentation and age at onset. For example, although many EODs are more likely to have Mendelian genetic and/or metabolic causes, the presence of comorbidities may drive the individual at risk for late-onset dementia to manifest the symptoms at an earlier age, which contributes further to the observed heterogeneity and may confound diagnostic investigation. A personalized medicine approach to diagnosis should therefore be considered depending on the age at onset, clinical presentation, and comorbidities. Genetic counseling and testing as well as specialized biochemical screening are often required, especially in those under the age of 40 and in those with a family history of autosomal dominant or recessive disease. Novel treatments in the drug development pipeline for EOD, such as genetic forms of Alzheimer's disease, should target the specific pathogenic cascade implicated by the mutation or biochemical defect.
\end{abstract}

\section{Introduction}

As older populations continue to grow worldwide, public concern about the increasing number of people with dementia also grows. Estimates state that there were 36 million people living with dementia globally in 2010, and it is further estimated that this number will increase to 66 million by 2030 and to 115 million by 2050 [1]. Dementia is a syndrome of progressive deterioration of cognitive function sufficient to impact on daily life and occupational functioning [1,2]. Alzheimer's disease (AD) is the most common type of dementia [3]; however, other common forms include frontotemporal lobar degeneration (FTLD), Lewy body spectrum disorders and vascular cognitive impairment. Although dementia mainly affects older populations, awareness for dementia cases that begin before the age of 65 is increasing [1].

\footnotetext{
*Correspondence: Mario.Masellis@sunnybrook.ca; Serge.gauthier@mcgill.ca ${ }^{2}$ Cognitive and Movement Disorders Neurology Clinic, Sunnybrook Health Sciences Centre, 2075 Bayview Avenue, Room A4 42, Toronto, ON, Canada M4N $3 \mathrm{M} 5$

${ }^{5}$ McGill Centre for Studies in Aging, McGill University, 6825 Boulevard LaSalle, Montreal, QC, Canada H4H 1R3

Full list of author information is available at the end of the article
}

Early-onset dementia (EOD) often refers to dementia becoming clinically manifested before age 65 , and the term young-onset dementia has been used for onset before age 45 [4]. For the purpose of this document, written for the Fourth Canadian Consensus Conference on the Diagnosis and Treatment of Dementia (CCCDTD4) that took place in May 2012 in Montreal [5], the terms will be used interchangeably, as was done by Rossor and colleagues in a recent review of the topic [6].

EODs pose several challenges for the clinician that may confound accurate diagnosis, including: clinical phenotypic heterogeneity within patients having the same underlying pathology, which is most often due to its variable distribution within the central nervous system (CNS); clinical phenotypic similarities between patients with different underlying pathologies due to redundancy of the neural circuits affected; genetic heterogeneity multiple genes can produce the same pathology; pleiotropic effects - the same mutation in a single gene in different individuals can be associated with a variety of different clinical presentations; allelic heterogeneity, whereby different mutations at the same locus produce different clinical features; confusion with psychiatric disease; and variability in the early age at onset (AAO) within and between clinical syndromes, which can range 
from early adulthood up to age 65. As such, it is critical that clinicians employ a consistent diagnostic approach when dealing with patients suffering from EODs. This will maximize the chances of making an accurate diagnosis, which will facilitate discussions with the patient and their family regarding prognosis, and, in rare instances, may allow for targeted therapies that modify the course of the underlying disease; for example, chelating therapy for Wilson's disease. This will also allow for the more effective use of symptomatic therapies, including both pharmacological and nonpharmacological ones, resulting in improved quality of life through avoidance or reduction of disease-associated or drugassociated complications. Achieving an accurate diagnosis will also facilitate referral to clinical geneticists as this has implications beyond the afflicted patient; family members may also be at risk of developing the disease or transmitting the disease-causing mutation to their offspring, and this may affect family planning and insurance-related and career-related decisions. Furthermore, with the exclusion of known pathologies using a systematic approach, it may also facilitate the identification of novel genetic diseases through inclusion of patients and their extended families in research studies.

In this article, we will contrast the complex etiologies for the dementias observed across the lifespan by providing a few examples of genetic risk factors and causative mutations in the common late-onset and less common early-onset neurodegenerative pathologies, respectively. We will also highlight the difficulties encountered in the diagnosis and management of patients with EOD, provide diagnostic approaches based on clinical, imaging, genetic and biochemical screening, and make several recommendations approved by the CCCDTD4.

\section{Epidemiology of dementia across the lifespan}

Most population-based studies on the prevalence of dementia have focused on patients who are over the age of 60. For example, the World Health Organization has estimated that the age-standardized prevalence of dementia tends to vary between 5 and $7 \%$ of the world's population aged 60 years and older [7]. Overall, very few population-based studies have been completed on the epidemiology of EOD. Of the studies completed to date, Harvey and colleagues estimated that the prevalence of dementia in those aged 30 to 64 was 54 per 100,000 people in the United Kingdom [8]. Similarly, Ikejima and colleagues found a prevalence rate of 42.3 per 100,000 individuals aged 20 to 64 in Japan [9]. Furthermore, The World Alzheimer Report has estimated that between 2 and $10 \%$ of all cases of dementia begin before the age of 65 [1]. For both EOD as well as late-onset forms, the consensus is that prevalence rates increase significantly with age, almost doubling every 5 years from 9/100,000 at age 30 to $156 / 100,000$ at age 60 to 64 [7]. Numerically, the most important causes of dementia are degenerative in nature at all ages, but reversible causes are relatively more prevalent in the young [6]. Figure 1 provides a schematic representation of prevalence rates of dementia based on age ranges.

\section{Late-onset versus early-onset dementia syndromes: etiological and therapeutic considerations}

Late-onset dementia is, for the most part, considered sporadic in nature with complex genetic and environmental (mostly unknown) risk factors. Genetic analysis of complex diseases may be complicated by many factors such as incomplete penetrance, multiple disease susceptibility loci, gene-environment interactions, and diagnostic uncertainties [10]. Recently, through the application of genome-wide association studies in very large, multicenter case-control cohorts, several gene risk variants for $\mathrm{AD}$ and Parkinson's disease have been identified, each of which confers an incremental risk to individuals possessing the risk alleles [11-15]. The genes include ones already known to be involved in the underlying pathology of these disorders - for example, apolipoprotein $\mathrm{E}(A P O E)$ for $\mathrm{AD}$ and alpha-synuclein (SNCA) for Parkinson's disease - as well as many novel genes. The exact role that these genes play and the regional effects that their variants have on the brain and secondarily on neurological and cognitive functions are mostly unknown. Strategies such as reverse phenotyping, whereby these risk alleles are associated with endophenotypes or biomarkers of disease such as neuroimaging, cerebrospinal fluid (CSF) proteomic and neuropsychological measures, are becoming increasingly important in the quest to dissect the mechanisms underlying the heterogeneity of the neurodegenerations $[16,17]$.

The current prevailing hypothesis is that the risk of developing a late-onset dementia, such as sporadic AD, is due to a weak genetic effect of each genome-wide association study-identified gene polymorphism that together across all genes synergizes to cause the symptoms and neurological decline. However, due to the nature of genome-wide association studies - specifically that there is clinical heterogeneity in the patients included - we hypothesize that it is more likely that each gene polymorphism or smaller subsets of the polymorphisms together with cerebrovascular risk factors (hypertension, diabetes, hypercholesterolemia, smoking, and obesity), breakdown of neuronal cellular repair mechanisms due to aging, and unknown environmental risks are responsible for several different pathogenic cascades to the final pathology of late-onset dementia. This hypothesis is illustrated in Figure 2.

In contrast, EODs are more likely to run in families and be inherited in a Mendelian fashion. As such, they are 

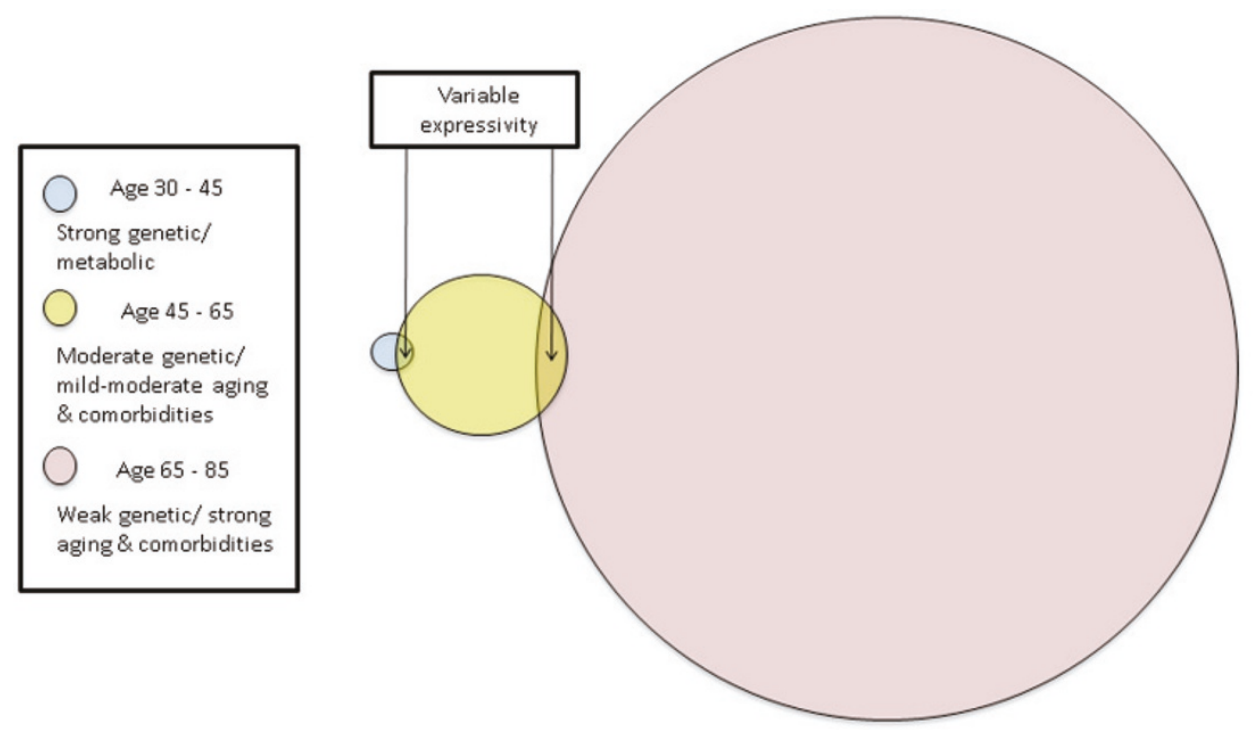

Figure 1. Prevalence rates of early-onset dementia and relative contribution from presumed etiological mechanisms. Schematic representation of the prevalence rates for early-onset dementia and the relative contribution from presumed etiological mechanisms in three different age ranges. Areas of circles represent the estimated prevalence rates within the specified age grouping.

more likely to arise from single gene defects, each of which carries a large effect in causing the early-onset presentation. Comorbidities such as cerebrovascular risk factors are rarer in the young and are less likely to contribute to the pathogenic cascade in comparison with late-onset dementias (see Figure 1). As a result, there is a higher probability that there will be a single (or only a few) pathogenic route(s) to the EOD syndrome (see Figure 2).

These important pathogenic differences between lateonset dementia and EODs have significant future therapeutic implications. Specifically, we anticipate that EODs with a hypothetical single (or few) route(s) of pathogenesis may be better targeted by disease-modifying drugs that are directed against the pathogenic cascade; for example, mAbs targeted against amyloid in early-onset familial Alzheimer's disease (EOFAD). In other words, with respect to pharmacotherapy a onesize-fits-all disease-based approach might be feasible, although there will probably be inter-individual differences in response due to genetic factors that influence the specific pharmacokinetic and pharmacodynamic properties of the drug, as well as disease characteristics such as AAO, and rates of clinical progression (see Figure 2) [18]. On the contrary, if the hypothesis relating to multiple pathogenic routes for the development of late-onset dementia is correct, then we anticipate that several different drugs will need to be targeted towards the different pathogenic cascades involved in the final common pathway to dementia in addition to aggressive management of underlying cerebrovascular risk factors; that is, a personalized medicine/disease-based approach (see Figure 2). We strongly believe that future research efforts will need to focus on disentangling the likely heterogeneous mechanisms for late-onset dementia before effective therapies will be demonstrated.

The arbitrarily determined chronological age cutoff values described in the Introduction that define EOD and late-onset dementia can be helpful in the diagnostic work-up because the younger the age of onset, the more likely the cause will be strongly genetic in origin and not infrequently due to familial neurodegenerative or neurometabolic disorders (see Figure 1) [19]. In considering these age cutoff values, however, biological age rather than chronological age must also be taken into consideration. For example, a patient aged 50 years with several uncontrolled cerebrovascular risk factors may have a more similar pathogenic cascade leading to dementia to someone who develops dementia in their 70 s, in comparison with someone who develops it at the age of 50 but does not have any significant medical comorbidities. There may be variable expressivity of the age of onset depending on the strength of the contributing genetic effects and the presence of comorbidities leading to clinical syndromes that overlap in terms of the age of onset, but may indeed be due to different etiologies as shown in Figure 1. We will now discuss the most common types of EODs, reviewing clinical, genetic, and pathological features.

\section{Early-onset familial Alzheimer's disease}

EOFAD is the most well-known group of persons with EOD because of the autosomal dominant pattern of 


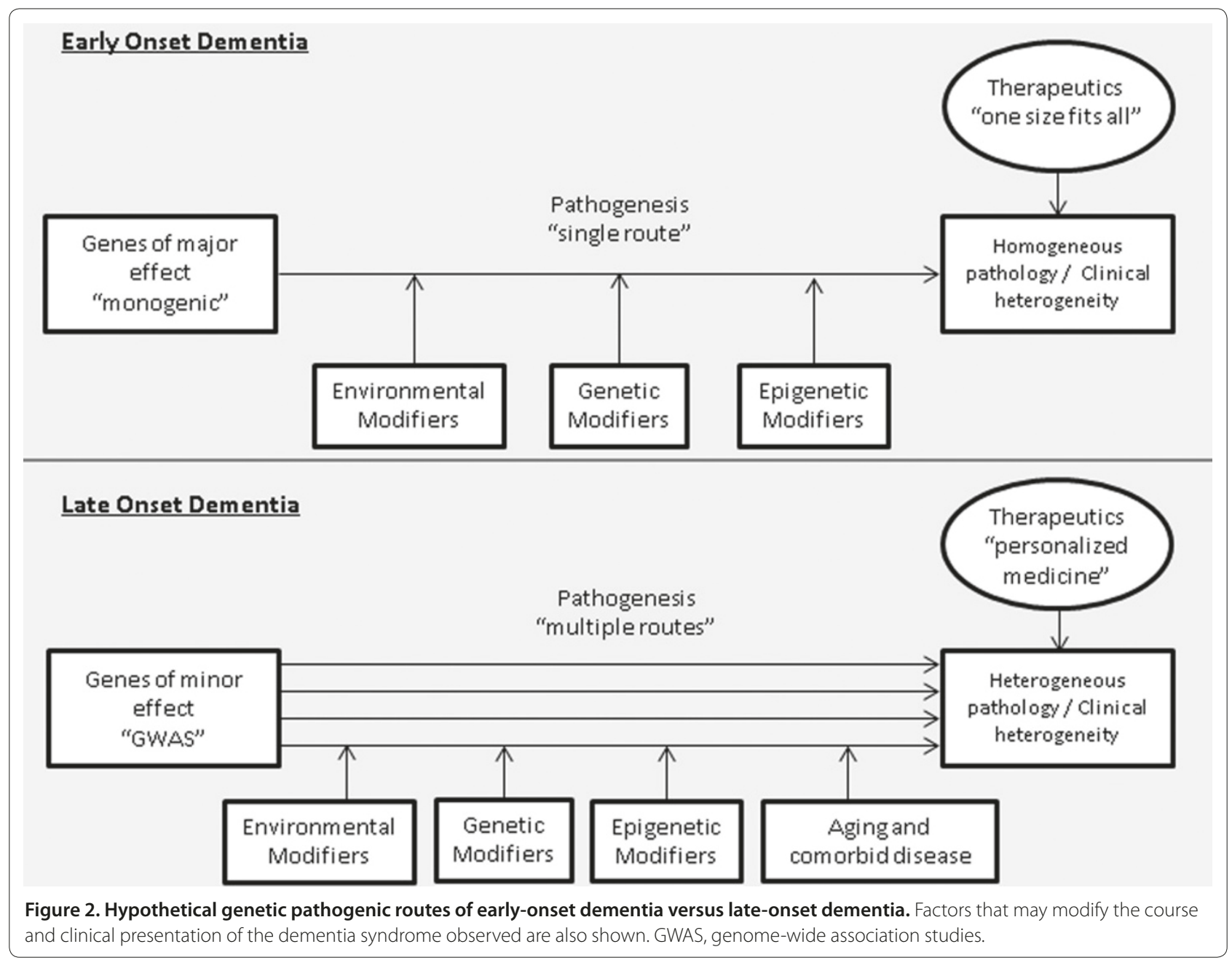

inheritance affecting first-degree relatives, the high penetrance of the three known major mutations, which are examined for in genetics clinics, and the recent interest in the progression of biomarkers through the asymptomatic, mild cognitive impairment and early dementia stages, studied as part of the Dominantly Inherited Alzheimer Network and the Alzheimer's Prevention Initiative [20-22]. Hopes are that studies such as this may lead to anti-amyloid and other drug trials in this group of EOFAD patients, who traditionally have been excluded from clinical trials.

EOFAD has been extensively reviewed by $\mathrm{Wu}$ and colleagues, the highlights of which are as follows [23]. EOFAD is a condition that represents up to $5 \%$ of all $\mathrm{AD}$ cases in clinical practice. To date, 230 mutations in presenilin (PS1, PS2) and amyloid precursor protein $(A P P)$ genes have been identified in EOFAD. The mutations within these three genes (PS1, PS2, APP) affect a common pathogenic pathway in APP synthesis and proteolysis, which leads to excessive production of amyloid beta. More recently, using exome sequencing, mutations in the Sortilin-related receptor LR11/SorLA (SORL1) were discovered in autosomal dominant, earlyonset $\mathrm{AD}$ index cases, who did not harbor mutations in the other AD-causing genes [24]. Initial interest in this gene was identified through a large case-control genetic association study of markers within SORL1 [25], and the more recent discovery might suggest that a few individuals included in this study harbored mutations that were in linkage disequilibrium with the studied markers.

For the most part, the clinical presentation of EOFAD is similar to that of sporadic AD, with an amnestic syndrome being common to both in the majority of cases although atypical $\mathrm{AD}$ variants are more common in early-onset cases [26]. However, there are some distinctive features including early AAO, positive family history, and a variety of noncognitive neurological symptoms and signs. Despite relatively similar biochemical defects, there is marked phenotypic heterogeneity among different mutations of EOFAD. Clinical symptoms start at an earlier age for carriers of PS1 mutations in comparison with those with $P S 2$ or APP mutations. Studies 
in presymptomatic mutation carriers reveal amyloid pathological biomarker abnormalities including positive uptake of Pittsburgh Compound B on positron emission tomography (PET) and lowering of amyloid beta in CSF at least 10 years before symptoms emerge [20].

\section{Frontotemporal lobar degeneration spectrum disorders}

In Canada, FTLD accounts for about $12 \%$ of referrals in those under age 70 to tertiary dementia clinics [27]. FTLD comprises a heterogeneous group of neurodegenerative pathologies that cause clinical dementia syndromes characterized by prominent decline in social conduct and behavior, including, for example, disinhibition, apathy, and hyperorality, and/or prominent language dysfunction, referred to as behavioral variant and primary progressive aphasia (PPA) variants of frontotemporal dementia, respectively $[28,29]$. As specified in the name, symptoms result from focal cortical and subcortical atrophy involving the frontal and temporal lobes, most often asymmetrically in the early disease stages with prominent right-sided involvement presenting as behavioral variant frontotemporal dementia and left-sided involvement as PPA. However, the neurodegenerative pathology relentlessly progresses to involve both sides and, therefore, disease evolution to mixed forms is the rule rather than the exception [30,31]. FTLD represents the second most common form of EOD after $\mathrm{AD}$ with $\mathrm{AAO}$ ranging from 45 to 64 years [32].

Familial inheritance of FTLD is even stronger than for $\mathrm{AD}$, representing up to $40 \%$ of all FTLD encountered clinically [33]. Within FTLD, heritability can also vary substantially between the different clinical syndromes observed [34]. To date, three genes have been identified to be responsible for the majority of autosomal dominant forms of FTLD: microtubule-associated protein tau $(M A P T)$, progranulin $(G R N)$, and the C9ORF72 gene [35-37]. Mutations in the valosin-containing protein $(V C P)$, chromatin modifying protein 2B (CHMP2B), transactive DNA-binding protein (TARDBP) and fusedin sarcoma $(F U S)$ have also been identified as rare causes of familial FTLD although most cases related to FUS are sporadic in nature [38]. In genetic FTLD, the reported range of age of onset is highly variable from 29 to 81 years, particularly in those with GRN or C9ORF72 mutations $[39,40]$. Findings of motoneuron disease may coexist with FTLD and have rarely been associated with GRN [41], TARDBP and CHMP2B mutation, but are commonly seen with C9ORF72 repeat expansions [33].

The discovery of the various FTLD-causing mutations has largely been driven by the genomic analysis of subgroups of patients classified according to the heterogeneous pathologies underlying FTLD. These can be largely divided into two broad subgroups: Tau-positive cases (can be associated with MAPT mutations), and Taunegative cases with ubiquitin and TDP43 inclusions (FTLD-TDP) can be associated with GRN and $V C P$ mutations, and C9ORF72 hexanucleotide repeat expansions $[33,38]$. Some cases of FTLD with Tau-negative, ubiquitin-positive inclusions may not demonstrate any TDP43 immunoreactivity, and FUS can be the pathological protein associated with FUS mutations [42]. Finally, there are cases of ubiquitin-positive FTLD without TDP43 and FUS immunoreactivity, and some of these cases can be associated with $C H M P 2 B$ mutations [33].

Corticobasal syndrome (CBS) and progressive supranuclear palsy (PSP) are atypical Parkinsonian syndromes that occur along the spectrum of FTLD due to overlapping pathologies and clinical presentations [43]. CBS presents with the combination of various cortical and extrapyramidal features usually with striking asymmetry [44]. The cortical features may include focal or asymmetric ideomotor apraxia, alien limb phenomenon, cortical sensory loss, visual or sensory hemi-neglect, constructional apraxia, and focal or asymmetric myoclonus [44]. The extrapyramidal features may consist of appendicular rigidity lacking prominent and sustained levodopa response, and appendicular dystonia [44]. An early dementia onset may be the most common initial presentation of CBS [45], and this often has overlapping features with FTLD such as a progressive nonfluent aphasia/apraxia of speech or a behavioral presentation [46]. PSP is characterized by progressive axial greater than appendicular rigidity, early postural instability with falls, dysphagia, and vertical supranuclear gaze palsy, which is the hallmark feature of this disease although it may often not emerge until late in the course [47]. Patients may also present with frontal behavioral abnormalities and executive cognitive decline as well as aphasia [47]. Although the clinical presentation of PSP is most probably due to an underlying Tauopathy, in particular PSP pathology [48], clinically defined CBS may be due to Tau pathologies (for example, corticobasal degeneration (CBD), Pick's disease, PSP), non-Tau pathologies (for example, FTLD-TDP) and mixed amyloid and Tau pathology (for example, AD), making it more pathologically heterogeneous [46]. CBS typically presents in the sixth to eighth decade of life and has a mean age of onset of approximately 63 years (standard deviation 7.7 years) [49], similar to that observed in PSP [50].

Genetic association studies of sporadic cases of CBD and PSP with the typical age of onset demonstrate that the MAPT $\mathrm{H} 1$ haplotype is over-represented in cases compared with controls [51,52]. However, since this is a common haplotype, it is probably not that useful to distinguish amongst the various atypical parkinsonian syndromes, although one small study (from the genetic 
standpoint) demonstrated a nonsignificantly higher odds ratio of the $\mathrm{H} 1 / \mathrm{H} 1$ genotype in the Richardson variant of PSP than in the PSP-Parkinsonism variant [47]. In the rare event that CBS and/or CBD pathology are observed to segregate in a family, other members are typically affected with FTLD and/or PSP demonstrating overlap in these conditions [53-60]. Tau pathology has been most commonly observed with CBD or PSP inclusions [56], with a few families demonstrating MAPT mutations [56]. Some families have demonstrated non-Tau pathology as well [53,55]. Mutations in GRN have been shown to segregate with CBS phenotypes in family members due to FTLD-Ubiquitin pathology [31]. Familial cases of CBS and PSP may have an earlier AAO than that of sporadic cases.

\section{Lewy body spectrum disorders: Parkinson's dementia and Lewy body dementia}

Parkinson's disease dementia (PDD) and dementia with Lewy bodies (DLB) demonstrate varying combinations of extrapyramidal, cognitive, neuropsychiatric, and autonomic symptoms. The distinguishing clinical feature between these disorders arbitrarily relates to the time of onset of motor symptoms. PDD presents with early parkinsonism (tremor, rigidity, bradykinesia) that responds well to dopaminergic therapy, followed by cognitive and neuropsychiatric decline at least 1 year after the motor onset [61]. In contrast, DLB presents with an early dementia consisting of fluctuations in attention and alertness as well as visual hallucinations [62]. Parkinsonism may be contemporary with the dementia or may develop later [62].

Clinical symptoms and signs of these diseases occur as a result of profound neurotransmitter dysfunction including dopaminergic systems (motor and executive dysfunction), serotonergic systems (mood and hallucinations), noradrenergic systems (gait, mood, and inattention), and cholinergic systems (hallucinations, inattention, reductions in semantic fluency, executive and visuospatial dysfunction) $[63,64]$. The neurotransmitter dysfunction occurs secondarily to the presence of brain stem, cortical and limbic Lewy bodies and Lewy neurites, which are comprised of pathological intraneuronal aggregates of alpha-synuclein [62]. There is increasing evidence that beta-amyloid plaques may also contribute to the dementia seen in PDD [65-67] and DLB [68]. As a result of this clinical and neuropathological overlap, DLB and PDD are considered disorders that occur along the spectrum of Lewy body disease and are classified as synucleinopathies.

Similar to AD, Lewy body spectrum disorders are typically of late onset and are, for the most part, considered sporadic in nature with complex genetic and unknown environmental factors that increase risk for disease. In a prospective study, PD patients with the $M A P T \mathrm{H} 1 / \mathrm{H} 1$ genotype had a significantly increased risk of developing dementia (odds ratio $=12.1$ ) and a more rapid rate of cognitive decline over the longitudinal assessment period [69]. A second prospective study did not find an association between change in Mattis Dementia Rating Scale version 2 scores over time and MAPT H1 haplotype in PD [70]. The inconsistent results for the MAPT H1 haplotype are probably due to small sample sizes in both studies; however, there remains the possibility that misdiagnosis of CBD or PSP patients as PDD or alternatively mixed Tau and Lewy body pathologies may be contributing to the discrepant results. A more recent pathological study has demonstrated an increased frequency of the $A P O E \& 4$ allele in DLB with AD pathological changes, pure DLB and PDD compared with controls, implicating a role for the $\varepsilon 4$ allele in lateonset sporadic forms of Lewy body spectrum disorders [71]. This further supports an overlap between AD and Lewy body spectrum disorders.

Although rarer than $\mathrm{AD}$ and frontotemporal dementia in patients younger than 65 years, early-onset Lewy body spectrum disorders have been described. Several earlyonset families segregating phenotypes of DLB and Parkinson's disease have been reported due to SNCA triplications [72] or the SNCA missense mutation, p.A53T [73]. A number of other early-onset families with Lewy body spectrum disorders have been identified, but a causative gene has yet to be identified [74]. In further support of the link between $\mathrm{AD}$ and Lewy body pathology, PS1, PS2, and $A P P$ gene mutations can cause a DLB phenotype due to mixed Lewy body and AD pathology [75-78].

More recent evidence is emerging for a role of heterozygous glucocerebrosidase (GBA1) mutations in Lewy body spectrum disorders [79-81]. A multicenter case-control study of 721 cases clinically diagnosed with DLB, several with pathological confirmation, and 151 cases of PDD demonstrated an increased risk of DLB and PDD in GBA1 mutation carriers compared with controls [82]. GBA1 mutation carriers had an earlier age of onset (63.5 years) than noncarriers (68.9 years) and also had higher Hoehn and Yahr stage disease and Unified Parkinson's Disease Rating Scale scores [82]. Lyzosomal dysfunction may therefore be involved in the pathogenic cascade leading to alpha-synuclein aggregation in the subgroup of patients with GBA1 mutations, although the specific mechanisms are not yet fully elucidated [83].

\section{Vascular cognitive impairment and mixed Alzheimer's with cerebral small vessel disease}

Mixed Alzheimer's with subcortical ischemic white matter disease (that is, small vessel disease (SVD)) is the most common type of late-onset dementia observed $[84,85]$ and is also probably responsible for a good 
proportion of early-onset cases in the later age ranges (for example, 50 to 65 years) because of the high prevalence of cerebrovascular risk factors in the general population [86]. Patients with this mixed dementia state often have significant impairments in episodic memory typical of $\mathrm{AD}$, but additionally demonstrate impairments in executive functions, psychomotor speed of processing, and mental flexibility (that is, frontal-subcortical dementia) [87-89].

Pure vascular cognitive impairment is comparatively uncommon in contrast to mixed AD with SVD, and usually presents with an insidious decline in cognition and a frontal-subcortical dementia with memory benefitting from cueing $[90,91]$. A stepwise trajectory of decline may less commonly be observed with vascular cognitive impairment [90,91]. Together with significant periventricular frontal white matter SVD burden and associated periventricular atrophy, an apraxia of gait may also be observed and this is often referred to as lower limb or vascular parkinsonism. This resembles the gait disorder observed in normal pressure hydrocephalus. Although the latter condition needs to be considered at differential diagnosis, vascular cognitive impairment/parkinsonism is often misdiagnosed as normal pressure hydrocephalus and a therapeutic lumbar puncture followed by gait assessment is required to differentiate the two entities.

Cerebrovascular disorders are probably the most heterogeneous of the pathologies that can cause dementia in the young. The reason for this heterogeneity is because of the large number of diseases that can result in overt strategic infarction (hemorrhagic or ischemic) and/or covert subcortical ischemic white matter disease (SVD) [92]. Discussing all of the stroke etiologies that can lead to young-onset vascular cognitive impairment is beyond the scope of this review. However, a few notable examples will be discussed briefly, including cerebral autosomal dominant arteriopathy with subcortical infarcts and leukoencephalopathy (CADASIL), cerebral vasculitis, and cerebral amyloid angiopathy. CADASIL is the most common genetic cause of young-onset vascular cognitive impairment and is associated with migraine, recurrent strokes, dementia, and often psychiatric features including psychosis [93]. Diagnosis is suggested through the appropriate history including that of the family, examination findings, as well as magnetic resonance imaging (MRI) showing lacunar-type infarctions and SVD that can be confluent as the disease progresses and that also involves the anterior temporal lobes (see Figure 3a) [93]. The diagnosis is confirmed through skin biopsy showing granular deposits in the basal lamina of small vessels and with the identification of $\mathrm{NOTCH} 3$ gene mutations [93].

Primary cerebral (CNS) vasculitis or angiitis is typically associated with headache, progressive encephalopathy, and multiple strokes [92,94]. Noninvasive and invasive cerebral angiography techniques can show the classic vessel beading pattern dependent on the size of the vessels involved (that is, medium-size to large-size vessels), and CSF often demonstrates a lymphocytic pleiocytosis and elevated protein levels [94]. In diagnostically challenging cases, brain biopsy remains the gold standard [94]. Histologically, a lymphocytic inflammatory process consisting of plasma cells, histiocytes, neutrophils, and eosinophils is most commonly seen, while the classic segmental granulomatous vasculitis with multinucleated giant cells is less often observed [94]. Secondary causes of vasculitis such as those associated with connective tissue diseases and infections must be excluded [94]. The utility of the various tests used to diagnose primary CNS vasculitis has been studied and, overall, the sensitivity, specificity, as well as positive and negative predictive values of each individual test are generally low [95]. Accurate diagnosis should therefore rely on the appropriate clinical history, examination findings, and correlation with multiple diagnostic investigations [95]. Finally, cerebral amyloid angiopathy can cause cerebral SVD and lobar micro and frank hemorrhages, and these pathologies can contribute to cognitive decline in patients with and without Alzheimer's pathology [85]. Later onset cases of cerebral amyloid angiopathy have been associated with $A P O E \varepsilon 4$ homozygotes [96], while earlier onset cerebral amyloid angiopathy cases with $\mathrm{AD}$ have been associated with duplications in the APP gene [97].

\section{Other causes of early-onset dementias}

A number of rare metabolic genetic conditions can also present as young-onset dementia. Providing a detailed account of these disorders is beyond the scope of this review, and an approach to investigating them has been provided by others [19]. However, a selected list of metabolic/genetic disorders that can present with progressive dementia in the young, organized by the most common neurological features observed, is summarized in Table 1. The table also presents the genetic/ metabolic defects, and other associated clinical features of these disorders, which may assist in the diagnostic work-up. The majority of these demonstrate autosomal recessive, X-linked, or mitochondrial inheritance. Ascertainment of a family history of consanguinity or marriage within a genetically homogeneous group - for example, Ashkenazi Jews - and absence of disease in a generation suggest autosomal recessive inheritance. If males are prominently, or more severely, affected than females, an $\mathrm{X}$-linked inheritance is likely, while maternal lineage supports mitochondrial disease. These rules of thumb may assist in screening for the appropriate genes and biochemical testing. Although these metabolic genetic 

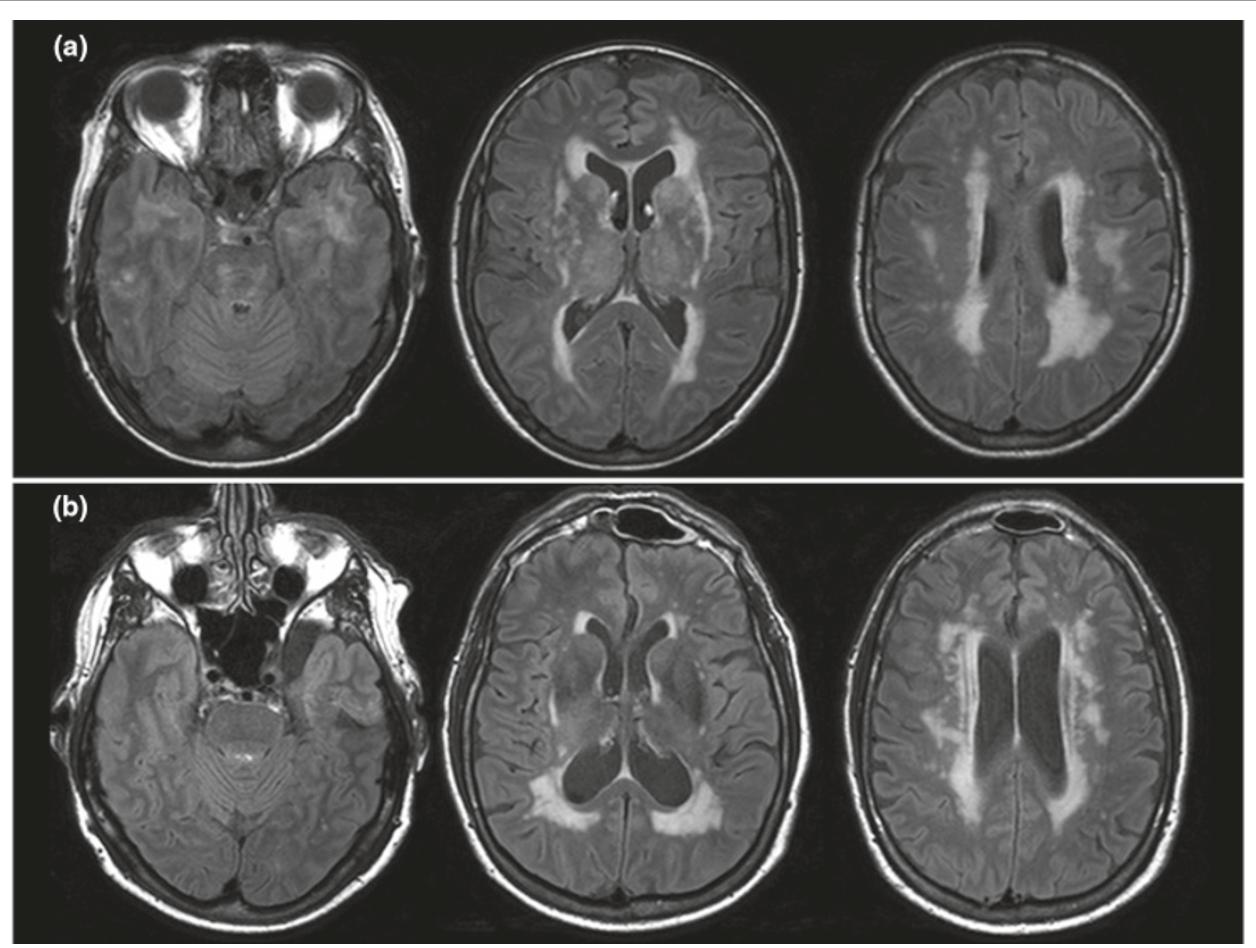

Figure 3. Subcortical ischemic vascular changes in CADASIL and vascular cognitive impairment due to small vessel disease. Axial T2/fluid-attenuated inversion recovery magnetic resonance imaging demonstrating subcortical ischemic vascular changes in (a) a patient with cerebral autosomal dominant arteriopathy with subcortical infarcts and leukoencephalopathy (CADASIL) and (b) a patient with vascular cognitive impairment due to small vessel disease. Anterior temporal lobe involvement distinguishes CADASIL from small vessel disease due to cerebrovascular risk factors.

diseases are relatively rare, their prevalence is higher in those under the age of 35 and therefore appropriate genetic testing and biochemical screening should be conducted based on the clinical presentation in affected individuals under this age (Table 1) [4]. Accurate diagnosis will allow proper genetic counseling and provide prognostic guidance to the family, which is an integral component in the management of dementia. These include disorders of amino acid and organic acid metabolism, lysosomal storage diseases, leukodystrophies, mitochondrial diseases, and disorders of metal metabolism. While many of these genetic metabolic diseases are multisystem disorders, most will also suffer a significant degree of cognitive impairment [98]. In some cases, such as Niemann-Pick type $C$, dementia can be the main and only clinical presentation.

In addition to genetic-based neurodegenerative diseases, other systemic diseases can also lead to progressive cognitive decline that mimics EOD. Some reviews, such as that of Fadil and colleagues [99], list as many as 61 causes of EODs. For example, infectious diseases such as HIV, Lyme and syphilis, autoimmune inflammatory diseases such as lupus with CNS involvement, paraneoplastic syndromes with limbic encephalitis, and sleep disorders such as obstructive sleep apnea can all lead to progressive cognitive impairment (Table 2). The autoimmune encephalopathies are another group of clinically heterogeneous disorders associated with cognitive impairment in the young and, although they can be paraneoplastic in nature, they are most often not associated with tumors [100]. Antibodies to components of $\mathrm{N}$-methyl-D-aspartate receptors, 2-amino-3-(3-hydroxy5-methyl-isoxazol-4-yl)propanoic acid receptors, gammaaminobutyric acid-type B receptors, glycine receptors, and voltage-gated potassium channel complexes can be detected in affected patients, and symptoms are responsive to treatment with immunomodulatory drugs [100]. This group of disorders therefore represents a treatable cause of encephalopathy in the young and should not be missed.

\section{Diagnostic process and genetic testing}

Since the differential diagnosis is wide, a systematic clinical and investigational approach is needed to ensure all potentially treatable conditions have been ruled out and to identify associated clinical features that may help to narrow down the differential diagnosis; that is, dementia-plus disorders [6]. The examination should 
Table 1. Less common genetic/neurometabolic causes of dementia, their clinical features, and genetic mutations

\begin{tabular}{llll}
\hline $\begin{array}{l}\text { Prominent neurological } \\
\text { features and disorders }\end{array}$ & Associated clinical features & $\begin{array}{l}\text { Chromosome / } \\
\text { inheritance }\end{array}$ & Protein / gene \\
\hline $\begin{array}{l}\text { Stroke } \\
\text { CADASIL [93] }\end{array}$ & Migraine, psychiatric symptoms & $\begin{array}{l}\text { 19p13.1-p13.2/ } \\
\text { autosomal dominant }\end{array}$ & $\begin{array}{l}\text { Notch 3 receptor } \\
\text { protein (NOTCH3) }\end{array}$
\end{tabular}

Screening and diagnostic tests

\section{Stroke}

CADASH [93]

autosomal dominant protein (NOTCH3)

Skin biopsy - granular deposits in basal lamina of small vessels; NOTCH3 mutation analysis

\section{Stroke, neuropathy}

Fabry disease [117]

MELAS [117] syndrome [125]
Skin changes, renal dysfunction, eye findings, heart disease, diarrhea, vomiting and weight loss, stroke and painful peripheral neuropathy

Short stature, strokes, seizures, migraine, myopathy, peripheral neuropathy, hearing loss, eye findings, cardiomyopathy and conduction abnormalities, diabetes es

\section{Xq22 / X-linked \\ a-galactosidase $\mathrm{A}$} (GLA)

mtDNA / mitochondrial (mtDNA tRNA)
Hepatosplenomegaly, thrombocytopenia, ataxia, anemia, bleeding, osteopenia, bone abnormalities, growth retardation

Tremor, ataxia, parkinsonism, peripheral Xq27.3 / X-linked neuropathy, dysautonomia
$1 \mathrm{q} 21$ / autosomal recessive
Glucocerebrosidase (GBA7)

Fragile X Menta Retardation 1 (FMR1)
Deficient a-galactosidase A activity in leukocytes and elevated urinary oligosaccharide (trihexoside) assay; GLA mutation analysis

Mitochondrial transfer RNA gene mutations

EEG; serum and CSF lactate/ pyruvate, mtDNA mutation analysis; muscle biopsy showing ragged red fibers

Deficient glucocerebrosidase activity in leukocytes; GBA1 mutation analysis

DNA analysis of CGG trinucleotide repeat expansion demonstrating 55 to 200 repeats (premutation range)

15q24.1 / autosomal recessive

Hexosaminidase A

Psychiatric symptoms, cerebellar, upper motor neuron, lower motor neuron, and/ or extrapyramidal findings

Depression, spasticity, ataxia, gait disorder, personality and behavior change, parkinsonism, seizures

$5 q 32$ / autosomal dominant

Colony-stimulating factor 1 receptor (CSFIR)

Palmitoyl-protein Facial dyskinesia, ataxia, extrapyramidal signs, myoclonic epilepsy, dysarthria onset neuronal ceroid lipofuscinosis [128]

Dentatorubralpallidoluysian atrophy [129]

Ataxia, choreoathetosis, psychiatric symptoms

1 p32 / autosomal recessive

12p13.31/ autosomal dominant thioesterase 1 (PPT1) in a minority; other genes unknown Atrophin-1 (ATN1)

2q35 / autosomal

Frontal and parietal white matter

DNA analysis of CAG trinucleotide recessive signs, psychiatric symptoms, seizures, cataracts, Achilles tendon xanthomas, diarrhea, osteopenia

Adrenoleukodystrophy [131]

Behavioral change, peripheral neuropathy, myelopathy, Addison's disease
Xq28 / X-linked

ATP-binding cassette transporter, subfamily D, Type 1 (ABCD1)

22.q13.31-qter and recessive

14q31 / autosomal recessive (CYP27A1) 10q22.1 / autosomal

Sterol 26-hydroxylase, mitochondrial

Pyramidal signs, peripheral neuropathy behavioral change, psychosis, ataxia, seizures, tremor

Krabbe disease / globoid cell leukodystrophy [132]
Aryl-sulfatase $\mathrm{A}(A R S A)$ or saposin B (PSAP)

Galactocerebroside $\beta$-galactosidase (GALC)
Visual problems, gait disorder, rigidity, ataxia, pyramidal signs, peripheral neuropathy
Hexosaminidase A levels; HEXA mutation screening hyperintensity on T2/FLAIR MRI; CSFIR mutation analysis

Tissue biopsy demonstrating ceroid lipofuscin repeat expansion demonstrating $\geq 48$ repeats

Elevated serum cholestanol and serum/urine bile alcohols; CYP27A1 mutation analysis

Evidence of dysmyelination on T2/FLAIR MRI (white matter hyperintensity in parieto-occipital, frontal or involving centrum semi-ovale or diffuse); elevated level of very long-chain fatty acids in leukocytes or fibroblasts; $A B C D 1$ mutation analysis

Leukocyte arylsulfatase A assay; urine for elevated sulfatides; ARSA or PSAP mutation analysis Leukocyte galactocerebroside $\beta$-galactosidase; GALC mutation analysis

Continued overleaf 
Table 1. Continued

\begin{tabular}{ll}
\hline $\begin{array}{l}\text { Prominent neurological } \\
\text { features and disorders }\end{array}$ & Associated clinical features \\
\hline Autosomal dominant & Multiple subtypes with most common \\
spinocerebellar ataxias & being: SCA1 - ataxia, pyramidal signs; \\
(SCA) [133] & SCA2 - tremor, ataxia, hyporeflexia, \\
& chorea, myoclonus, dystonia, retinal \\
& degeneration, cardiac failure; SCA3 - \\
& peripheral neuropathy, parkinsonism, \\
& diplopia, ataxia, dystonia, pyramidal signs, \\
& psychiatric symptoms; SCA7 - chorea, \\
& parkinsonism, dystonia, ataxia, pyramidal \\
& signs, seizures
\end{tabular}

Ataxia, chorea, supranuclear gaze palsy

\begin{tabular}{lll}
$\begin{array}{l}\text { Chromosome / } \\
\text { inheritance }\end{array}$ & Protein / gene & Screening and diagnostic tests \\
\hline Multiple loci; & SCA1 - Ataxin-1 & DNA analysis of CAG trinucleotide \\
SCA1 - 6p22.3; & (ATXN1); SCA2 - & repeat expansion in relevant \\
SCA2 - 12q24.12; & Ataxin-2 (ATXN2); & genes \\
SCA3 - 14q32.12. & SCA3 - Ataxin-3 & \\
SCA7 - 3p14.1 $/$ & (ATXN3); SCA7 - & \\
autosomal dominant & Ataxin-7 (ATXN7) &
\end{tabular}

Skin fibroblast assay for intracellular cholestero
Niemann-Pick type C [119] Cerebellar ataxia, dysarthria, dementia, psychiatric disturbances, supranuclear gaze palsy and splenomegaly

\section{$18 q 11$ and $14 q 24.3 / \quad N P C 1$ and NPC2. \\ autosomal recessive respectively}

$13 q 14.3$ / autosomal recessive

Parkinsonism, dystonia, chorea, tremor, psychosis, liver dysfunction, ocular examination for Kayser-Fleischer rings

ATPase, $\mathrm{Cu}^{2+}-$ accumulation (filipin staining); or gene mutation analysis transporting beta polypeptide, (ATP7B)

Screening: serum ceruloplasmin, urinary copper; brain MRI shows 'face of the giant panda'sign

Confirmatory: liver biopsy and ATP7B mutation analysis

\section{Parkinsonism, dystonia}

Pantothenate

kinase-associated

neurodegeneration [134]

Dysarthria, psychiatric disturbance, rigidity, dystonia, chorea, gait disturbance

20p13-p12.3/ autosomal recessive Pantothenate kinase 2
(PANK2)

4p16.3 / autosomal Huntingtin (HTT) dominant repeat expansion demonstrating
DNA analysis of CAG trinucleotide $\geq 36$ repeats

Table presents some less common genetic/neurometabolic causes of dementia, their clinical features and genetic mutations grouped according to prominent neurological features. CADASIL, cerebral autosomal dominant arteriopathy with subcortical infarcts and leukoencephalopathy; CSF, cerebrospinal fluid; EEG, electroencephalogram; FLAIR, fluid-attenuated inversion recovery; MELAS, mitochondrial encephalopathy with lactic acidosis; mtDNA, mitochondrial DNA.

look for evidence of associated neurological and nonneurological features, such as parkinsonism and involvement of other organ systems, respectively. A basic screen for treatable causes of dementia that may be precipitating or aggravating cognitive symptoms should be completed in all patients. High-quality structural MRI should be completed in all patients to rule out structural lesions and to identify neuroanatomical signatures of the different dementia syndromes, while functional (single photon emission computed tomography (SPECT)/PET) neuroimaging should be carried out to investigate for the specific perfusion/metabolic signatures, respectively. Electroencephalogram and CSF analysis is recommended in the majority of patients with EOD to rule out epileptic, inflammatory, and infectious causes and to further refine the differential diagnosis. More specialized biochemical/ genetic testing for neurometabolic disorders will be dependent on AAO, family history, and associated clinical features (Table 1). There is also evidence from a large, retrospective case series that brain biopsy is potentially useful when diagnosis cannot be made by standard investigations and may reveal treatable diagnoses in about $10 \%$ of cases [101]. We also strongly recommend longitudinal follow-up, because in the very early stages of all EOD pathologies there may be considerable overlap and not all clinical features will have necessarily emerged. Diagnostic specificity will therefore improve with subsequent assessments in the early to mid stages of the disease process.

Cognitive screening and, preferably, neuropsychological testing should be completed to fully understand the cognitive profile involved. Neuropsychometric testing is also helpful in tracking disease progression and, potentially, response to treatment. Cognitive impairment can be broadly classified into two major subclasses based on the brain regions involved. 'Subcortical dementia' results 
Table 2. Some systemic diseases that may lead to progressive cognitive impairment and dementia

\begin{tabular}{|c|c|c|c|}
\hline System & Examples & Associated symptoms & Diagnostic tests \\
\hline CNS vascular disease & $\begin{array}{l}\text { Primary and secondary CNS } \\
\text { vasculitis }\end{array}$ & Headaches, focal neurological deficits & $\begin{array}{l}\text { MRl; cerebral angiography; CSF analysis; brain } \\
\text { biopsy; connective tissue disease screen } \\
\text { (for example, ANA, C3/C4, RF, c-ANCA and } \\
\text { p-ANCA, ENA-4 screen, cryoglobulins) }\end{array}$ \\
\hline \multirow[t]{3}{*}{ Infection } & $\begin{array}{l}\text { HIV-associated neurocognitive } \\
\text { disorders }\end{array}$ & $\begin{array}{l}\text { Variable, constitutional symptoms, } \\
\text { with or without opportunistic } \\
\text { infections }\end{array}$ & HIV screen; plasma HIV viral load; CD4 counts \\
\hline & Neurosyphilis & Tabes dorsalis & Serum RPR; MHA-TP; CSF VDRL \\
\hline & Whipple's disease & $\begin{array}{l}\text { Gastrointestinal symptoms, } \\
\text { weight loss, and polyarthralgia; } \\
\text { oculomasticatory and oculofacial- } \\
\text { skeletal myorhythmia in only 20\%, } \\
\text { but highly specific }\end{array}$ & $\begin{array}{l}\text { Duodenal biopsy showing granular foamy } \\
\text { macrophages with PAS-positive inclusions; } \\
\text { CSF PCR for Tropheryma whipplei }\end{array}$ \\
\hline Neoplastic & Primary CNS lymphoma & Headaches; focal neurological deficits & CSF analysis; brain/meningeal biopsy \\
\hline \multirow[t]{3}{*}{ Autoimmune / paraneoplastic } & Hashimoto encephalitis & Thyroid abnormalities & $\begin{array}{l}\text { Anti-microsomal antibody; anti-thyroglobulin } \\
\text { antibody }\end{array}$ \\
\hline & Limbic encephalitis & $\begin{array}{l}\text { Cancer (breast, lung, testicular, } \\
\text { teratoma colon, gynecological) }\end{array}$ & $\begin{array}{l}\text { Anti-Hu, anti-Ri, anti-Yo, anti-Ma1, anti-Ma2, } \\
\text { anti-VGKC, anti-CV2, anti-amphiphysin, anti- } \\
\text { NMDAR, anti-AMPAR, anti-GAD antibodies }\end{array}$ \\
\hline & Lupus with CNS involvement & Multiple organ systems & ANA; ENA; CSF analysis; MRI \\
\hline \multirow[t]{2}{*}{ Endocrine and nutritional } & Hypothyroidism & $\begin{array}{l}\text { Fatigue, weight gain, skin and hair } \\
\text { changes, depression }\end{array}$ & TSH; free T4 \\
\hline & B12 deficiency & $\begin{array}{l}\text { Fatigue, macrocytic anemia, } \\
\text { 'beefsteak' tongue, subacute } \\
\text { combined degeneration of spinal } \\
\text { cord }\end{array}$ & $\mathrm{B} 12$ \\
\hline
\end{tabular}

AMPAR, 2-amino-3-(3-hydroxy-5-methyl-isoxazol-4-yl)propanoic acid receptors; ANA, antinuclear antibodies; ANCA, anti-neutrophil cytoplasmic antibodies; CNS, central nervous system; CSF, cerebrospinal fluid; ENA, extractable nuclear antigens; MHA-TP, microhemagglutination assay; MRI, magnetic resonance imaging; NMDAR, N-methyl-D-aspartate receptors; PAS, periodic acid-Schiff; RF, rheumatoid factor; RPR, Rapid Plasma Reagin; TSH, thyroid stimulating hormone; VDRL, Venereal Disease Research Laboratory test.

from injury to the white matter pathways and damage to the basal ganglia and thalamic structures with psychomotor slowing, frontal dysexecutive syndrome, and memory retrieval difficulties. Alternatively, cortical dementia is characterized by problems in specific cognitive domains (for example, Alzheimer disease with episodic memory impairment) with relative preservation of processing speed. We will now outline clinical pearls and investigational approaches used in specialist memory and movement disorder clinics in Canada to assist with the diagnostic work-up of EOD. The approaches will focus mainly on slowly progressive forms of dementia (for example, >12 months) and not on rapidly progressive forms, such as Creutzfeldt-Jakob disease, which have been discussed elsewhere [102]. The profile of cognitive deficits based on history and observed on neuropsychometric testing in the early stages of young-onset dementia will serve as the initial diagnostic starting point and will now be expanded upon based on the presence of associated clinical features, neuroimaging, and laboratory investigations.

\section{Early-onset dementias/syndromes characterized by predominant memory deficits}

Most patients with cognitive difficulties (or their families) will complain of poor memory. However, when a patient with insidious EOD has amnesia as the primary complaint and this is corroborated on episodic memory testing, which demonstrates no or minimal benefit from cueing, then early-onset AD should be considered high on the differential diagnosis (Figure 4). Often there are no other associated clinical features and their absence may support a typical Alzheimer's presentation [26]. The MRI and functional imaging signature of typical AD, reviewed by McKhann and colleagues [103], is summarized in Figure 4. Figure $5 \mathrm{~b}$ shows mesiotemporal atrophy on MRI of a patient with EOFAD due to PS1 mutation. Routine CSF studies should be normal, but specialized research testing of CSF demonstrates reduced amyloid-beta levels and increased total-tau and phospho-tau levels [103]. Research PET scans may be obtained that demonstrate retention of ligands specific for amyloid, such as Pittsburgh Compound B, indicative of increased fibrillar 


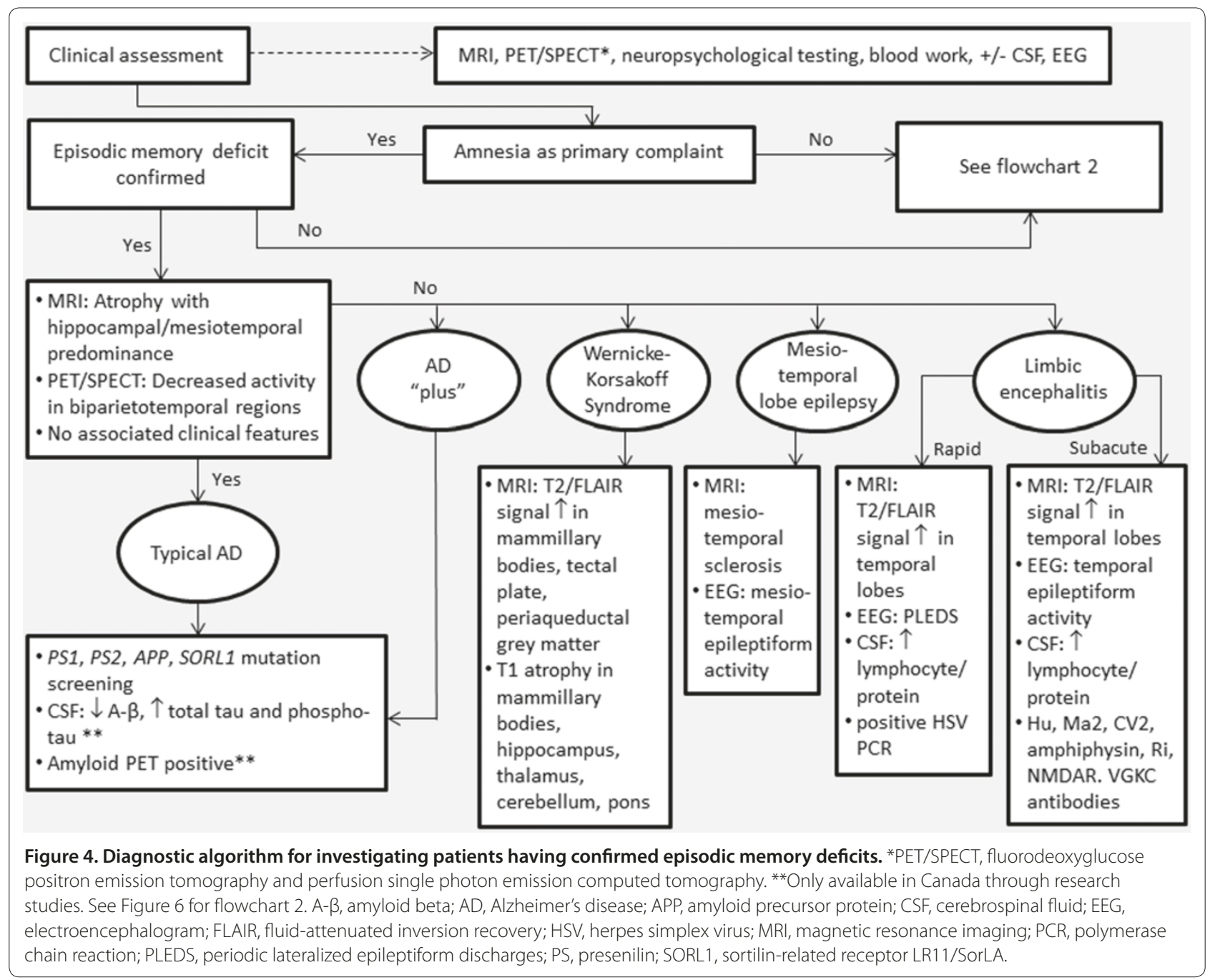

amyloid brain accumulation [103]. The research CSF and PET studies are not currently approved in Canada for the investigation and diagnosis of early-onset or late-onset $\mathrm{AD}$ and should be considered mainly for diagnostically challenging cases depending on availability and funding.

The presence of a family history suggesting autosomal dominant $\mathrm{AD}$ should prompt mutation screening for PS1, PS2, APP, and SORL1 in that order (Figure 4). Even in the absence of a strong family history, $\mathrm{AD}$ mutation screening should be strongly considered especially when the age of onset is very early and there are no associated medical comorbidities. If there is a history of alcoholism or severe malnutrition, then Wernicke-Korsakoff syndrome or alcohol-related dementia should also be considered on the differential diagnosis although confabulation is commonly observed in this condition and is not typical of AD (Figure 4). Furthermore, ophthalmoplegia, ataxia, and signs of chronic liver disease may be present and therefore should be looked for on examination. MRI imaging in Wernicke-Korsakoff syndrome shows several characteristic features that distinguish it from $\mathrm{AD}$ (Figure 4) [104]. Ataxia has also been observed in some cases of EOFAD associated with PS1 mutations, and genetic testing should be considered for this in the absence of an alcohol or malnutrition history (referred to as AD plus in Figure 4) [23].

EOFAD may also be associated with several other clinical features (referred to as AD plus in Figure 4) [23]. If there is a history of seizures then PS1 and PS2 mutation screening should be considered once other diagnoses such as temporal lobe epilepsy and limbic encephalitis due to paraneoplastic, autoimmune, or viral etiologies have been excluded (Figure 4). In mesiotemporal lobe epilepsy, there will often be a history suggestive of simple or complex partial seizures and symptoms of memory loss may occur in association with or be aggravated by ictal events $[105,106]$. Limbic encephalitis may present with episodic memory disturbance, seizures, confusion, and psychiatric disturbances [107]. A subacute course is typical for paraneoplastic-mediated and autoimmune-mediated 

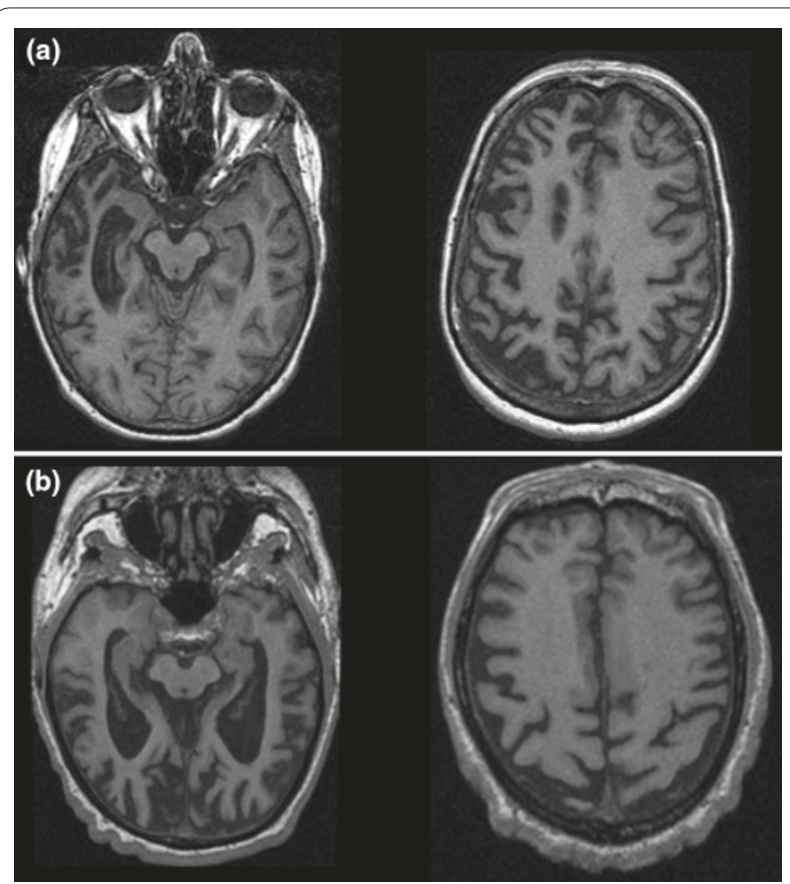

Figure 5. Contrasting atrophy patterns for behavioral variant frontotemporal dementia and early-onset familial Alzheimer's disease. Axial T1 magnetic resonance imaging contrasting atrophy patterns for (a) a patient with behavioral variant frontotemporal dementia due to progranulin (GRN) mutation and (b) a patient with early-onset familial Alzheimer's disease due to presenilin (PS1) mutation. (a) Striking asymmetry in frontotemporal and parietal lobes associated with GRN mutations. (b) More mesiotemporal and posterior predilection associated with PS1 mutations.

etiologies (that is, autoimmune encephalopathies) with several autoantibodies identified, and a more acute course with fever is consistent with viral causes, such as herpes simplex, which should not be missed and always investigated with CSF sampling (Figure 4) and covered empirically with anti-viral therapy, such as acyclovir [108].

Early-onset AD with movement disorders such as parkinsonism or myoclonus and/or psychiatric features such as hallucinations and psychosis may be seen with PS1 and PS2 mutations [23]. AD with spastic paraparesis or aphasia has been associated with PS1 mutations [23]. Finally, $A D$ with intracerebral hemorrhage has been observed with APP mutations or duplications [23]. Appropriate mutation screening for EOFAD genes may therefore be guided by these clinical associations referred to as AD plus in Figure 4.

\section{Early-onset dementias/syndromes characterized by cognitive deficits in other domains}

The approach to EODs with deficits in other cognitive domains is more complex than those associated with primary memory problems. There are far more diseases that fall under this category and the clinical features of these diseases can overlap significantly with prominent executive dysfunction as a main finding in most cases, alone or in combination with other deficits. Furthermore, there are also early-onset atypical variants of AD that fall under this highly heterogeneous group, which makes sorting out the differential diagnosis more challenging [26]. Since most of these EOD syndromes described in this section are due to non-Alzheimer's pathology, we direct you to the recent consensus guidelines on the diagnosis and management of disorders associated with dementia that have been proposed by the European Federation of Neurological Societies-European Neurological Society task force [109]. We will first discuss the diagnostic work-up for some of the more pure nonamnestic EOD syndromes (at least in their earliest stages) and will then discuss those that present with mixed deficits as well as other associated clinical features. Figures 6 and 7 present algorithms that can further aid in the diagnosis of nonamnestic presentations.

PPAs are clinically and pathologically heterogeneous in nature and are most likely to be due to FTLD, although variants of $\mathrm{AD}$ may also cause language disturbances. It is not uncommon that activities of daily living of afflicted patients may be preserved for a number of years apart from those relying on language function, although in most patients additional clinical features, such as behavioral dysregulation, executive dysfunction, apraxia and parkinsonism, can eventually emerge. The nonfluent variant (progressive nonfluent aphasia) presents with agrammatic and halting, effortful speech (Figure 6) [28]. There may be an associated apraxia of speech characterized by articulatory groping, dysprodic errors, and distorted speech sounds [110]. Pathologies that have been associated with mainly sporadic forms of the nonfluent and/or apraxia of speech variant of PPA are Tau-positive FTLD, as well as CBD and PSP $[28,110]$. FTLD-TDP due to GRN mutations has also been observed with the nonfluent PPA variant, although this is less common (Figure 6) [30,111]. Impaired naming to confrontation and single-word comprehension characterizes the semantic variant of PPA (semantic dementia; Figure 6) [28]. In sporadic forms FTLD-TDP pathology prevails [28], although familial cases have been associated with Tau-positive FTLD and MAPT mutations (Figure 6) [112]. Finally, the logopenic variant of PPA (logopenic aphasia) presents with impaired repetition of sentences and phrases as well as with difficulties in retrieving single words in spontaneous speech and naming [28]. The associated neuroimaging signatures of these PPA variants are summarized in Figure 6. In PPA cases, genetic testing should be guided by a positive family history of autosomal dominant disease and clinical presentation, with GRN and C9ORF72 mutation screening in nonfluent 


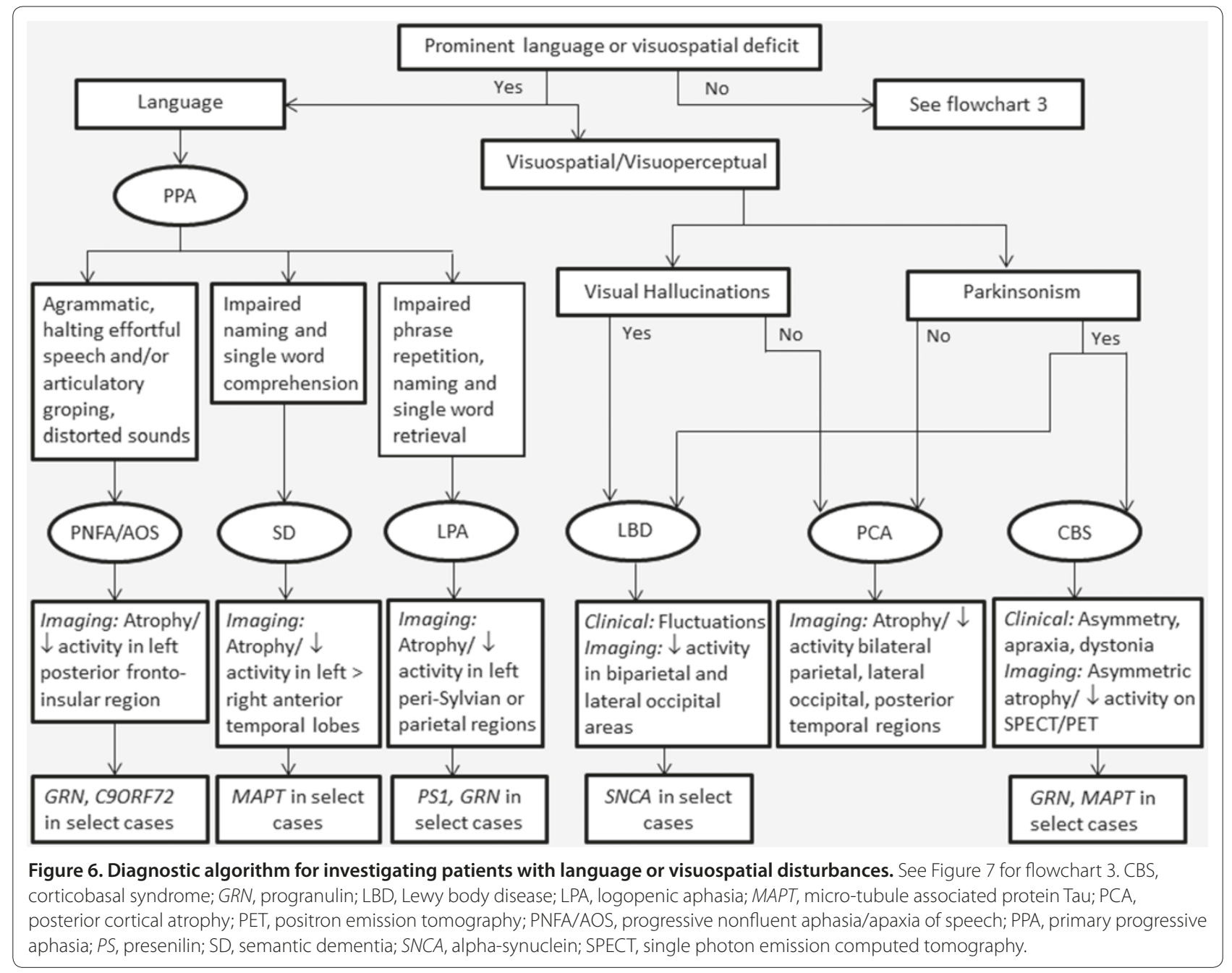

cases and with MAPT screening in semantic variant cases (Figure 6). PS1 and GRN mutation screening may be considered in select cases of logopenic aphasia (Figure 6) [23].

If attention, working memory, and executive function deficits are prominent, then the diagnostic approach is strongly guided by associated clinical features and structural and functional imaging. If behavioral features such as disinhibition, apathy, personality change, loss of self-regulation, and social impropriety are observed with executive dysfunction, and if MRI shows right frontal and anterior temporal atrophy worse than on the left (Figure 5a) with similar regions showing reduced activity on SPECT/PET, then behavioral variant frontotemporal dementia is high on the differential diagnosis (Figure 7). Appropriate genetic testing for GRN and MAPT mutations as well as hexanucleotide repeat expansions in C9ORF72 should be performed, especially if there is a strong autosomal dominant family history (Figure 7) [113]. The order of FTLD genetic testing should be guided by the clinical and familial history, examination, and MRI findings. GRN mutations are associated with more markedly asymmetric frontotemporal atrophy that also involves the parietal lobes (Figure 5a) and cases that eventually may evolve clinical features of CBS, whereas cases with MAPT mutations tend to have less atrophy and a stronger predilection for temporal areas with more focal involvement [38]. Finally, both familial and sporadic cases with C9ORF72 repeat expansions have more variable presentations including slowly progressive variants [114] and prominent neuropsychiatric illness [115], as well as association with motoneuron disease; atrophy tends to be more symmetrical involving the dorsolateral, medial, and orbitofrontal lobes [116]. The primary psychoses, such as bipolar disorder and schizophrenia, can also present with prominent behavioral features and are also considered in the differential diagnosis.

Vascular cognitive impairment also demonstrates prominent dysexecutive features and is suggested by the appropriate clinical history of cerebrovascular risk 


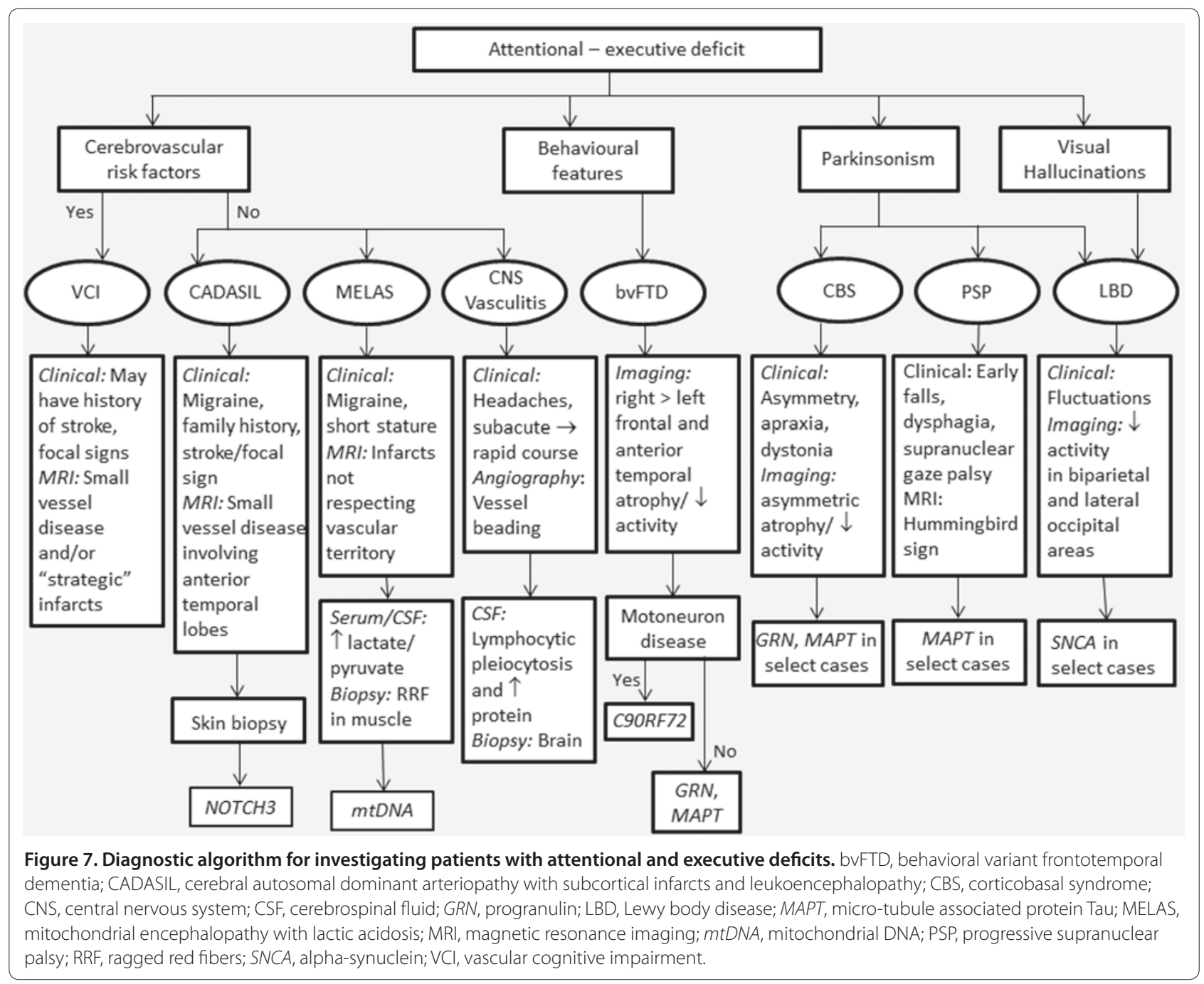

factors, stroke and/or focal neurological deficits conforming to specific arterial territories (Figure 7). In the absence of this clinical history and findings, MRI of the brain will invariably show SVD (Figure 3b) and/or cortical infarcts if they are located within the so-called silent regions (Figure 7). If cerebrovascular risk factors are not present, then CADASIL and CNS vasculitis should be considered (Figure 7). Patients with migraine, short stature, and strokes that do not respect vascular territories should be investigated with CSF and serum studies, particularly looking for increased lactate and pyruvate. A high lactate:pyruvate ratio is consistent with mitochondrial encephalopathy, lactic acidosis and strokelike episodes; diagnosis is made through skeletal muscle biopsy demonstrating ragged red fibers, and genetic testing should examine for mutations in the mitochondrial DNA genes, MT-TL1 ( $80 \%$ of cases) or MTND5 (Figure 7) [117]. APP duplications or mutations should be screened for if the EOD syndrome is associated with lobar hemorrhages (that is, cerebral amyloid angiopathy).

If executive dysfunction and parkinsonism (tremor, rigidity, akinesia/bradykinesia, and/or gait disorder) is evident on the examination, then atypical Parkinsonianrelated dementias are highest on the differential diagnosis (Figures 6 and 7). The most common subtype will be disorders falling under the Lewy body spectrum. The presence of visual hallucinations, fluctuations in attention and alertness, visuospatial deficits, rapid eye movement behavioral disorder, and dysautonomia are associated clinical features common to this spectrum. Not all features are always present, which broadens the differential diagnosis. The cognitive and neuropsychiatric symptoms of DLB often, but not always, respond to cholinesterase inhibitors and the response is usually more marked than that seen in AD. PDD patients will have a more robust response to levodopa and may develop postural instability as a late feature; on-off 
fluctuations and dyskinesias may be observed. DLB usually has at least a partial response to levodopa with significantly less motor complications, such as dyskinesia; postural instability may be an early feature. Dopamine agonists and amantadine typically produce increased confusion, sedation, and hallucinations so their use should be cautioned in PDD and DLB. Levodopa may also produce these symptoms, but usually to a much lesser degree. Impulse control disorders observed in PDD due to excessive dopaminergic therapy, especially with dopamine agonists, may also contribute to the behavioral and cognitive executive disorder, confounding the diagnosis. SPECT and PET studies of PDD and DLB show hypoperfusion and hypometabolism, respectively, in biparietal regions extending into the lateral occipital cortex (Figures 6, 7, and 8c). Mesiotemporal atrophy may be seen and this may suggest concomitant AD pathology. An electroencephalogram often shows generalized slowing. Reduced putaminal binding of presynaptic dopamine transporter ligands on SPECT may also be used to help differentiate DLB from AD [118], but this modality is currently not available in Canada. We would only recommend genetic testing in clinically typical Lewy body disease if there is a family history of at least two first-degree relatives affected. SNCA triplications and mutations may be screened. If other family members have AD phenotypes then PS1, PS2, and APP screening may be considered.

If the dysexecutive Parkinsonian syndrome is not associated with cognitive fluctuations or hallucinations, then CBS or PSP should alternatively be considered. CBS typically demonstrates striking lateralization of clinical findings. Atrophy on T1 sequences and subcortical T2/ fluid-attenuated inversion recovery signal changes on MRI representing gliosis, as well as hypoperfusion/ hypometabolism on functional imaging, are typically worse contralateral to the most affected side of the body and affect frontoparietal areas more than temporal areas (Figures 6, 7, and 8a). If the rigidity is present in axial muscles with nuchal hyperextension and frontalis overactivity, then PSP should be considered even in the absence of the vertical supranuclear gaze palsy. MRI imaging typically demonstrates the so-called humming bird sign evident on midline sagittal sections and is due to atrophy involving the midbrain (Figure 7 and 8d) [47]. Levodopa responsiveness is poor in CBS and PSP and, if it is present, it is usually not sustained. Niemann-Pick disease type $\mathrm{C}$ also often has a vertical supranuclear gaze palsy present as well as cerebellar ataxia, dysarthria, psychiatric disturbances, and splenomegaly (Table 1) [119]. Diagnostic testing of suspected cases of NiemannPick type $C$ should be performed via skin biopsy with culturing of fibroblasts and examination for intracellular cholesterol accumulation (filipin staining) in addition to screening for mutations in the NPC1 (95\% of cases) and NPC2 (5\%) genes (Table 1) [119]. Other FTLD spectrum disorders, such as FTLD with Parkinsonism-TDP or Parkinsonism-Tau linked to chromosome 17 (GRN mutations and MAPT mutations, respectively), can also be associated with atypical parkinsonism. However, there are usually associated symptoms and MRI findings of FTLD observed.

Wilson's disease should be screened for in cases of age of onset $<40$ years. Investigations reveal low ceruloplasmin levels, elevated 24-hour urinary copper levels, and the presence of Kayser-Fleischer rings through slitlamp examination [120]. Atypical parkinsonism with a frontal-subcortical dementia, psychosis, and a wingflapping/beating tremor may be observed [120]. Liver function tests and abdominal ultrasound should also be carried out. MRI of the brain may show the face of the giant panda sign (Figure 8b) [120]. Diagnosis is made via liver biopsy showing copper accumulation and through demonstration of recessive mutations in the ATP7B gene [120]. Wilson's disease is treatable acutely with chelating therapy and chronically with maintenance zinc supplementation, and therefore the diagnosis should not be missed. Later onset cases of Wilson's disease have also been described so we recommend a low threshold for screening if the Parkinsonian syndrome is not consistent with some of the more common atypical Parkinsonian variants in those older than 40 years.

EODs that present with prominent visuospatial and visuoperceptual deficits on history and neuropsychological testing represent another neurodegenerative syndrome termed posterior cortical atrophy (see Figure 6). Patients often present to psychiatrists and ophthalmologists before being assessed by neurologists due to the atypical presentation of this entity. Posterior cortical atrophy typically occurs between ages 50 and 65 years and is often associated with features of Bálint's syndrome (asimultagnosia, optic ataxia, and oculomotor apraxia), Gerstmann's syndrome (acalculia, right-left confusion, finger agnosia, and agraphia), alexia, limb apraxia (both ideational and ideomotor), and working memory deficits [121-123]. MRI findings are summarized in Figure 6. Fluorodeoxyglucose PET and perfusion SPECT show hypometabolism and hypoperfusion in similar regions to those affected on the MRI, with functional deficits also observed in the middle and posterior cingulum, the pulvinar, as well as the middle and superior frontal gyri corresponding to the frontal eye fields [121,122]. Posterior cortical atrophy is most commonly associated with $\mathrm{AD}$ pathology; however, $\mathrm{DLB}, \mathrm{CBD}$, and prion disease have also been observed [121].

There are many other exceedingly rare dementia-plus conditions that can present with early AAO and associated frontal-executive features with and without 

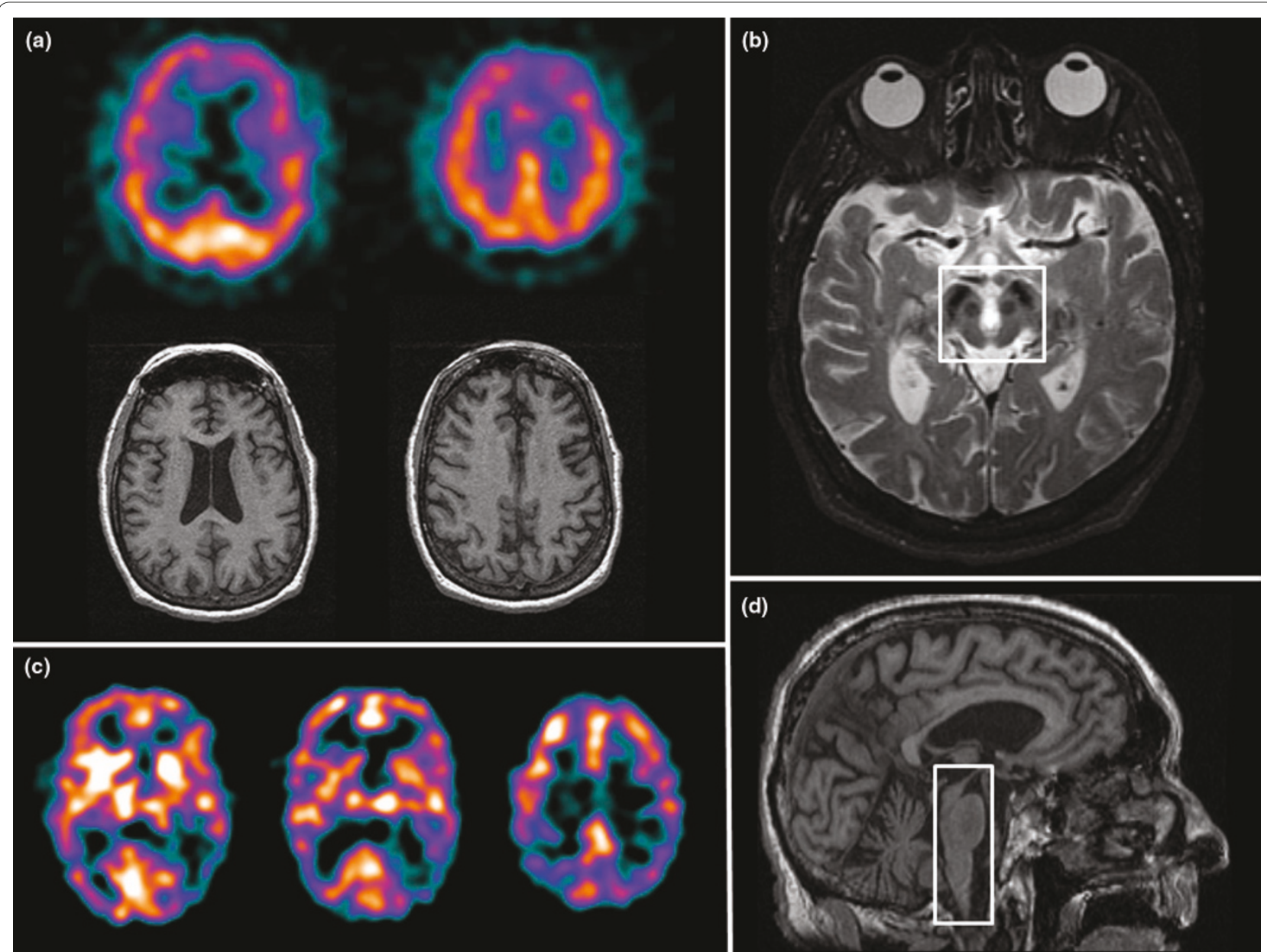

Figure 8. Structural and functional neuroimages of patients presenting with early onset dementia associated with atypical parkinsonism. (a) Axial 99mTc-ethylcysteinate dimer (99mTc-ECD) perfusion single photon emission computed tomography (SPECT) and T1 magnetic resonance imaging (MRI) of a patient with pathologically confirmed corticobasal degeneration. (b) Axial T2 MRI of a patient with Wilson's disease demonstrating the face of the giant panda sign. (c) Axial 99mTc-ECD perfusion SPECT of a patient with early-onset Lewy body spectrum disorder demonstrating biparietal hypoperfusion extending into lateral occipital areas. (d) Sagittal T1 MRI of a patient with progressive supranuclear palsy demonstrating the humming bird sign.

neuropsychiatric features. Table 1 describes the clinical and imaging features, biochemical defects, and genetic mutations observed in these rare dementia-plus conditions organized according to most common neurological associations.

\section{Recommendations regarding early-onset dementia approved by the CCCDTD}

- All patients with EOD should be referred to a specialist (memory or movement disorders) clinic, preferably one with access to genetic counseling and testing as well as biochemical screening when appropriate.

- The investigation of genetic etiologies should be guided by the detailed assessment and investigations (MRI, functional imaging, laboratory investigations, and so forth) performed by the specialist neurologist in conjunction with the clinical geneticist, who will provide information to the patient and their family regarding implications of the potential findings.

- The cost of genetic counseling and testing should be covered by public funding.

- If AAO is $<40$ years then rare genetic metabolic disorders should always be investigated if the specific dementia diagnosis is not evident through other investigations.

- Physicians should be sensitive to the special issues associated with EOD, in particular with regard to loss of employment and access to support services appropriate for that age group.

- Considering the rarity of EOD, a national registry for interested at-risk individuals, mutation carriers and symptomatic patients will facilitate therapeutic research.

- This registry should be supported by public funding. 


\section{Conclusions and future directions}

The diagnosis and management of EODs is challenging but is an important component of neurologic referrals. This review considers the diagnostic investigations that are currently available to most neurologists, geriatricians, and geriatric psychiatrists worldwide in their clinical practice. It is fortunate that many genetic markers are emerging for $\mathrm{AD}$ and FTLD, and there is increasing knowledge about biomarkers that can potentially be tracked years before clinical symptoms emerge in EOFAD. The emerging biomarkers include fluorodeoxyglucose PET and amyloid PET, dopamine transporter SPECT, and CSF proteomic studies, which currently are not readily available in Canada for clinical use. However, we anticipate that these biomarkers will be added to the current standard of care as they are further validated. Future reviews will address these novel imaging and proteomic technologies. These advances will allow for a more aggressive therapeutic and personalized medicine approach that may impact on the management of the more common EODs.

\section{Abbreviations}

$A A O$, age at onset; $A D$, Alzheimer's disease; $A P O E$, apolipoprotein $E_{\text {; }}$ $A P P$, amyloid precursor protein; CADASIL, cerebral autosomal dominant arteriopathy with subcortical infarcts and leukoencephalopathy; CBD, corticobasal degeneration; CBS, corticobasal syndrome; CCCDTD4, Fourth Canadian Consensus Conference on the Diagnosis and Treatment of Dementia; CHMP2B, chromatin modifying protein 2B; CNS, central nervous system; CSF, cerebrospinal fluid; DLB, dementia with Lewy bodies; EOD early-onset dementia; EOFAD, early-onset familial Alzheimer's disease; FTLD, frontotemporal lobar degeneration; FUS, fused-in sarcoma; GBA1, glucocerebrosidase; GRN, progranulin; mAb, monoclonal antibody; MAPT, microtubule-associated protein Tau; MRI, magnetic resonance imaging; PDD, Parkinson's disease dementia; PET, positron emission tomography; PPA, primary progressive aphasia; PSP, progressive supranuclear palsy; PS, presenilin; SNCA, alpha-synuclein; SORL1, sortilin-related receptor LR11/SorLA; SPECT, single photon emission computed tomography; $S V D$, small vessel disease; $T A R D B P$, transactive DNA-binding protein; VCP, valosin-containing protein.

\section{Competing interests}

The authors declare that they have no competing interests.

\section{Acknowledgements}

The authors thank the staff of the McGill Center for Studies in Aging for their support during the CCCDTD. They would also like to thank Ms Alicia McNeely, Mr Christopher Scott and Mr Gregory Szilyagi for assisting with the creation of the neuroimage figures. MM receives research support from the Parkinson Society Canada, the Canadian Institutes of Health Research $(\mathrm{CIHR})$, the Ministry of Economic Development and Innovation of Ontario, the Consortium of Canadian Centres for Clinical Cognitive Research, and Teva Pharmaceuticals, and receives salary support from the Department of Medicine (Sunnybrook Health Sciences Centre and University of Toronto) and the Sunnybrook Foundation. SEB receives research support from the CIHR, the Heart and Stroke Foundation of Canada, the Department of Medicine (Sunnybrook Health Sciences Centre and University of Toronto), and the Brill Chair in Neurology, University of Toronto. SG is supported by the CIHR. G-YRH is supported by a Clinical Genetics Investigatorship from the CIHR.

\section{Declarations}

This article has been published as part of Alzheimer's Research \& Therapy Volume 5 Supplement 1, 2013: Background documents to the 4th Canadian Consensus Conference on the Diagnosis and Treatment of Dementia (CCCDTD4). The full contents of the supplement are available online at http://alzres.com/supplements/5/S1.
Publication charges for the supplement were funded by the Canadian Consensus Conference on the Diagnosis and Treatment of Dementia (CCCDTD). Although residual conference funds used include contributions from pharmaceutical companies, no commercial organization has been involved in the selection of participants, choice of topics, preparation of background papers or recommendations. In kind support was also provided by the Canadian Dementia Knowledge Translation Network, and the offices of Drs Serge Gauthier (McGill University), Christopher Patterson (McMaster University) and Howard Chertkow (McGill University), whose role as Guest Editors involved the coordination of the project without involvement in the journal's standard peer review process which applied for all articles.

\section{Authors' contributions}

All authors contributed to the preparation of this manuscript before and after the CCCDTD4 took place.

\section{Author details}

1 L.C. Campbell Cognitive Neurology Clinic, Sunnybrook Health Sciences Centre, 2075 Bayview Avenue, Room A4 21, Toronto, ON, Canada M4N 3M5. ${ }^{2}$ Cognitive and Movement Disorders Neurology Clinic, Sunnybrook Health Sciences Centre, 2075 Bayview Avenue, Room A4 42, Toronto, ON, Canada M4N 3M5. ${ }^{3}$ Department of Medicine (Neurology), Brain Sciences Research Program, Sunnybrook Health Sciences, Centre University of Toronto, Toronto, ON, Canada. ${ }^{4}$ Neurogenetics Section, Centre for Addiction and Mental Health, University of Toronto, 250 College Street, R-30, Toronto, ON, Canada M5T1R8. ${ }^{5}$ McGill Centre for Studies in Aging, McGill University, 6825 Boulevard LaSalle, Montreal, QC, Canada H4H 1R3. ${ }^{6}$ Translational Neuroimaging Laboratory, Douglas Research Institute, McGill University, Montreal, QC, Canada. ${ }^{7}$ Alzheimer Group Inc., Montreal, QC, McConnell Brain Imaging Centre, Montreal Neurological Institute, Montreal, QC, Canada. ${ }^{8}$ Division of Neurology, Faculty of Medicine, University of British Columbia, Vancouver, BC, Canada. ${ }^{9}$ Department of Medical Genetics, University of British Columbia, Vancouver, BC, Canada. ${ }^{10}$ Rotman Research Institute, Baycrest Centre for Geriatric Care, Toronto, ON, Canada. "Department of Geriatrics, McMaster University, ON, Canada

Published: 31 July 2013

\section{References}

1. Prince M, Jackson J: World Alzheimer's Report 2009. London: Alzheimer's Disease International; 2009.

2. Batsch N, Mittelman M: World Alzheimer's Report 2012 - Overcoming the Stigma of Dementia. London: Alzheimer's Disease International; 2012.

3. Blennow K, de Leon MJ, Zetterberg H: Alzheimer's disease. Lancet 2006 368:387-403

4. Kelley BJ, Boeve BF, Josephs KA: Young-onset dementia: demographic and etiologic characteristics of 235 patients. Arch Neurol 2008, 65:1502-1508.

5. Gauthier S, Patterson C, Chertkow H, Gordon M, Herrmann N, Rockwood K, Rosa-Neto P, Soucy JP: Recommendations of the $4^{\text {th }}$ Canadian consensus conference on the diagnosis and treatment of dementia (CCCDTD4). Can J Geriatrics 2012, 15:120-126.

6. Rossor MN, Fox NC, Mummery CJ, Schott JM, Warren JD: The diagnosis of young-onset dementia. Lancet Neurol 2010, 9:793-806.

7. World Health Organization: Dementia: A Public Health Priority. Geneva: World Health Organization; 2012.

8. Harvey RJ, Skelton-Robinson M, Rossor MN: The prevalence and causes of dementia in people under the age of 65 years. J Neurol Neurosurg Psychiatry 2003, 74:1206-1209.

9. Ikejima C, Yasuno F, Mizukami K, Sasaki M, Tanimukai S, Asada T: Prevalence and causes of early-onset dementia in Japan: a population-based study. Stroke 2009, 40:2709-2714.

10. Nothen MM, Propping P, Fimmers R: Association versus linkage studies in psychosis genetics. J Med Genet 1993, 30:634-637.

11. International Parkinson's Disease Genomics Consortium: A two-stage metaanalysis identifies several new loci for Parkinson's disease. PLoS Genet 2011 7:e1002142.

12. Do CB, Tung JY, Dorfman E, Kiefer AK, Drabant EM, Francke U, Mountain JL, Goldman SM, Tanner CM, Langston JW, Wojcicki A, Eriksson N: Web-based genome-wide association study identifies two novel loci and a substantial genetic component for Parkinson's disease. PLoS Genet 2011, 7:e1002141.

13. Hollingworth P, Harold D, Sims R, Gerrish A, Lambert JC, Carrasquillo MM, 
Abraham R, Hamshere ML, Pahwa JS, Moskvina V, Dowzell K, Jones N, Stretton A, Thomas C, Richards A, Ivanov D, Widdowson C, Chapman J, Lovestone S, Powell J, Proitsi P, Lupton MK, Brayne C, Rubinsztein DC, Gill M, Lawlor B, Lynch A, Brown KS, Passmore PA, Craig D, et al:: Common variants at ABCA7, MS4A6A/MS4A4E, EPHA1, CD33 and CD2AP are associated with Alzheimer's disease. Nat Genet 2011, 43:429-435.

14. Naj AC, Jun G, Beecham GW, Wang LS, Vardarajan BN, Buros J, Gallins PJ, Buxbaum JD, Jarvik GP, Crane PK, Larson EB, Bird TD, Boeve BF, Graff-Radford NR, De Jager PL, Evans D, Schneider JA, Carrasquillo MM, Ertekin-Taner N, Younkin SG, Cruchaga C, Kauwe JS, Nowotny P, Kramer P, Hardy J, Huentelman MJ, Myers AJ, Barmada MM, Demirci FY, Baldwin CT, et al:: Common variants at MS4A4/MS4A6E, CD2AP, CD33 and EPHA1 are associated with late-onset Alzheimer's disease. Nat Genet 2011, 43:436-441.

15. Nalls MA, Plagnol V, Hernandez DG, Sharma M, Sheerin UM, Saad M, SimonSanchez J, Schulte C, Lesage S, Sveinbjornsdottir S, Stefansson K, Martinez M, Hardy J, Heutink P, Brice A, Gasser T, Singleton AB, Wood NW: Imputation of sequence variants for identification of genetic risks for Parkinson's disease: a meta-analysis of genome-wide association studies. Lancet 2011, 377:641-649.

16. Joober R: The 1000 Genomes Project: deep genomic sequencing waiting for deep psychiatric phenotyping. J Psychiatry Neurosci 2011, 36:147-149.

17. Schulze TG, McMahon FJ: Defining the phenotype in human genetic studies: forward genetics and reverse phenotyping. Hum Hered 2004, 58:131-138.

18. Lam B, Hollingdrake E, Kennedy JL, Black SE, Masellis M: Cholinesterase inhibitors in Alzheimer's disease and Lewy body spectrum disorders: the emerging pharmacogenetic story. Hum Genomics 2009, 4:91-106.

19. Ridha B, Josephs KA: Young-onset dementia: a practical approach to diagnosis. Neurologist 2006, 12:2-13.

20. Bateman RJ, Xiong C, Benzinger TL, Fagan AM, Goate A, Fox NC, Marcus DS, Cairns NJ, Xie X, Blazey TM, Holtzman DM, Santacruz A, Buckles V, Oliver A, Moulder K, Aisen PS, Ghetti B, Klunk WE, McDade E, Martins RN, Masters CL, Mayeux R, Ringman JM, Rossor MN, Schofield PR, Sperling RA, Salloway S, Morris JC: Clinical and biomarker changes in dominantly inherited Alzheimer's disease. N Engl J Med 2012, 367:795-804.

21. Fleisher AS, Chen K, Quiroz YT, Jakimovich LJ, Gomez MG, Langois CM, Langbaum JB, Ayutyanont N, Roontiva A, Thiyyagura P, Lee W, Mo H, Lopez L, Moreno S, Acosta-Baena N, Giraldo M, Garcia G, Reiman RA, Huentelman MJ, Kosik KS, Tariot PN, Lopera F, Reiman EM: Florbetapir PET analysis of amyloid-beta deposition in the presenilin 1 E280A autosomal dominant Alzheimer's disease kindred: a cross-sectional study. Lancet Neurol 2012 11:1057-1065

22. Reiman EM, Quiroz YT, Fleisher AS, Chen K, Velez-Pardo C, Jimenez-Del-Rio M, Fagan AM, Shah AR, Alvarez S, Arbelaez A, Giraldo M, Acosta-Baena N, Sperling RA, Dickerson B, Stern CE, Tirado V, Munoz C, Reiman RA, Huentelman MJ, Alexander GE, Langbaum JB, Kosik KS, Tariot PN, Lopera F: Brain imaging and fluid biomarker analysis in young adults at genetic risk for autosomal dominant Alzheimer's disease in the presenilin 1 E280A kindred: a case-control study. Lancet Neurol 2012, 11:1048-1056.

23. Wu L, Rosa-Neto P, Hsiung GY, Sadovnick AD, Masellis M, Black SE, Jia J, Gauthier S: Early-onset familial Alzheimer's disease (EOFAD). Can J Neurol Sci 2012, 39:436-445.

24. Pottier C, Hannequin D, Coutant S, Rovelet-Lecrux A, Wallon D, Rousseau S, Legallic S, Paquet C, Bombois S, Pariente J, Thomas-Anterion C, Michon A, Croisile B, Etcharry-Bouyx F, Berr C, Dartigues JF, Amouyel P, Dauchel H, Boutoleau-Bretonniere C, Thauvin C, Frebourg T, Lambert JC, Campion D: High frequency of potentially pathogenic SORL1 mutations in autosomal dominant early-onset Alzheimer disease. Mol Psychiatry 2012, 17:875-879.

25. Rogaeva E, Meng Y, Lee JH, Gu Y, Kawarai T, Zou F, Katayama T, Baldwin CT, Cheng R, Hasegawa H, Chen F, Shibata N, Lunetta KL, Pardossi-Piquard R, Bohm C, Wakutani Y, Cupples LA, Cuenco KT, Green RC, Pinessi L, Rainero I, Sorbi S, Bruni A, Duara R, Friedland RP, Inzelberg R, Hampe W, Bujo H, Song $Y Q$, Andersen OM, et al:: The neuronal sortilin-related receptor SORL1 is genetically associated with Alzheimer disease. Nat Genet 2007, 39:168-177.

26. Lam B, Masellis M, Freedman M, Stuss DT, Black SE: Clinical, imaging, and pathological heterogeneity of the Alzheimer's disease syndrome. Alzheimers Res Ther 2013, 5:1.

27. Feldman H, Levy AR, Hsiung GY, Peters KR, Donald A, Black SE, Bouchard RW Gauthier SG, Guzman DA, Hogan DB, Kertesz A, Rockwood K: A Canadian cohort study of cognitive impairment and related dementias (ACCORD): study methods and baseline results. Neuroepidemiology 2003, 22:265-274.
28. Gorno-Tempini ML, Hillis AE, Weintraub S, Kertesz A, Mendez M, Cappa SF, Ogar JM, Rohrer JD, Black S, Boeve BF, Manes F, Dronkers NF, Vandenberghe R, Rascovsky K, Patterson K, Miller BL, Knopman DS, Hodges JR, Mesulam MM, Grossman M: Classification of primary progressive aphasia and its variants. Neurology 2011, 76:1006-1014

29. Rascovsky K, Hodges JR, Knopman D, Mendez MF, Kramer JH, Neuhaus J, van Swieten JC, Seelaar H, Dopper EG, Onyike CU, Hillis AE, Josephs KA, Boeve BF, Kertesz A, Seeley WW, Rankin KP, Johnson JK, Gorno-Tempini ML, Rosen H, Prioleau-Latham CE, Lee A, Kipps CM, Lillo P, Piguet O, Rohrer JD, Rossor MN, Warren JD, Fox NC, Galasko D, Salmon DP, et al.: Sensitivity of revised diagnostic criteria for the behavioural variant of frontotemporal dementia. Brain 2011, 134:2456-2477.

30. GabryelewiczT, Masellis M, Berdynski M, Bilbao JM, Rogaeva E, St GeorgeHyslop P, Barczak A, Czyzewski K, Barcikowska M, Wszolek Z, Black SE, Zekanowski C: Intra-familial clinical heterogeneity due to FTLD-U with TDP-43 proteinopathy caused by a novel deletion in progranulin gene (PGRN). J Alzheimers Dis 2010, 22:1123-1133.

31. Masellis M, Momeni $P$, Meschino W, Heffner R, Jr, Elder J, Sato C, Liang $Y$, St George-Hyslop P, Hardy J, Bilbao J, Black S, Rogaeva E: Novel splicing mutation in the progranulin gene causing familial corticobasal syndrome. Brain 2006, 129:3115-3123.

32. Rosso SM, Donker KL, Baks T, Joosse M, de K, I, Pijnenburg Y, de JD, Dooijes D, Kamphorst W, Ravid R, Niermeijer MF, Verheij F, Kremer HP, Scheltens P, van Duijn CM, Heutink P, van Swieten JC: Frontotemporal dementia in The Netherlands: patient characteristics and prevalence estimates from a population-based study. Brain 2003, 126:2016-2022.

33. Seelaar H, Rohrer JD, Pijnenburg YA, Fox NC, van Swieten JC: Clinical, genetic and pathological heterogeneity of frontotemporal dementia: a review. J Neurol Neurosurg Psychiatry 2011, 82:476-486.

34. Rohrer JD, Guerreiro R, Vandrovcova J, Uphill J, Reiman D, Beck J, Isaacs AM, Authier A, Ferrari R, Fox NC, Mackenzie IR, Warren JD, de SR, Holton J, Revesz T, Hardy J, Mead S, Rossor MN: The heritability and genetics of frontotemporal lobar degeneration. Neurology 2009, 73:1451-1456.

35. Baker M, Mackenzie IR, Pickering-Brown SM, Gass J, Rademakers R, Lindholm C, Snowden J, Adamson J, Sadovnick AD, Rollinson S, Cannon A, Dwosh E, Neary D, Melquist S, Richardson A, Dickson D, Berger Z, Eriksen J, Robinson T, Zehr C, Dickey CA, Crook R, McGowan E, Mann D, Boeve B, Feldman H, Hutton M: Mutations in progranulin cause tau-negative frontotemporal dementia linked to chromosome 17. Nature 2006, 442:916-919.

36. Hutton M: Missense and splice site mutations in tau associated with FTDP-17: multiple pathogenic mechanisms. Neurology 2001, 56:S21-S25.

37. Jesus-Hernandez M, Mackenzie IR, Boeve BF, Boxer AL, Baker M, Rutherford NJ, Nicholson AM, Finch NA, Flynn H, Adamson J, Kouri N, Wojtas A, Sengdy P, Hsiung GY, Karydas A, Seeley WW, Josephs KA, Coppola G, Geschwind DH, Wszolek ZK, Feldman H, Knopman DS, Petersen RC, Miller BL, Dickson DW, Boylan KB, Graff-Radford NR, Rademakers R: Expanded GGGGCC hexanucleotide repeat in noncoding region of C9ORF72 causes chromosome 9p-linked FTD and ALS. Neuron 2011, 72:245-256.

38. Rohrer JD, Warren JD: Phenotypic signatures of genetic frontotemporal dementia. Curr Opin Neurol 2011, 24:542-549.

39. Hsiung G-Y R, Feldman HH: GRN-related frontotemporal dementia. In GeneReviews at GeneTests: Medical Genetics Information Resource [database online]. Seattle: University of Washington; 2007. [http://www.genetests.org]

40. Hsiung GY, Jesus-Hernandez M, Feldman HH, Sengdy P, Bouchard-Kerr P, Dwosh E, Butler R, Leung B, Fok A, Rutherford NJ, Baker M, Rademakers R, Mackenzie IR: Clinical and pathological features of familial frontotemporal dementia caused by C9ORF72 mutation on chromosome 9p. Brain 2012, 135:709-722.

41. Cannon A, Fujioka S, Rutherford NJ, Ferman TJ, Broderick DF, Boylan KB, GraffRadford NR, Uitti RJ, Rademakers R, Wszolek ZK, Dickson DW: Clinicopathologic variability of the GRN A9D mutation, including amyotrophic lateral sclerosis. Neurology 2013, 80:1771-1777.

42. Van Langenhove T, van der Zee J, Van Broeckhoven C: The molecular basis of the frontotemporal lobar degeneration-amyotrophic lateral sclerosis spectrum. Ann Med 2012, 44:817-828.

43. Kertesz A: Pick Complex: an integrative approach to frontotemporal dementia: primary progressive aphasia, corticobasal degeneration, and progressive supranuclear palsy. Neurologist 2003, 9:311-317.

44. Boeve BF, Lang AE, Litvan I: Corticobasal degeneration and its relationship to progressive supranuclear palsy and frontotemporal dementia. Ann Neurol 2003, 54(Suppl 5):S15-S19. 
45. Grimes DA, Lang AE, Bergeron CB: Dementia as the most common presentation of cortical-basal ganglionic degeneration. Neurology 1999, 53:1969-1974

46. Kertesz A, Martinez-Lage P, Davidson W, Munoz DG: The corticobasal degeneration syndrome overlaps progressive aphasia and frontotemporal dementia. Neurology 2000, 55:1368-1375.

47. Williams DR, Lees AJ: Progressive supranuclear palsy: clinicopathological concepts and diagnostic challenges. Lancet Neurol 2009, 8:270-279.

48. Dickson DW, Ahmed Z, Algom AA, Tsuboi Y, Josephs KA: Neuropathology of variants of progressive supranuclear palsy. Curr Opin Neurol 2010 23:394-400.

49. Wenning GK, Litvan I, Jankovic J, Granata R, Mangone CA, McKee A, Poewe W, Jellinger K, Ray CK, D'Olhaberriague L, Pearce RK: Natural history and survival of 14 patients with corticobasal degeneration confirmed at postmortem examination. J Neurol Neurosurg Psychiatry 1998, 64:184-189.

50. Litvan I, Mangone CA, McKee A, Verny M, Parsa A, Jellinger K, D'Olhaberriague $L$, Chaudhuri KR, Pearce RK: Natural history of progressive supranuclear palsy (Steele-Richardson-Olszewski syndrome) and clinical predictors of survival: a clinicopathological study. J Neurol Neurosurg Psychiatry 1996, 60:615-620.

51. Di Maria E, Tabaton M, Vigo T, Abbruzzese G, Bellone E, Donati C, Frasson E, Marchese R, Montagna P, Munoz DG, Pramstaller PP, Zanusso G, Ajmar F, Mandich P: Corticobasal degeneration shares a common genetic background with progressive supranuclear palsy. Ann Neurol 2000 47:374-377.

52. Houlden H, Baker M, Morris HR, MacDonald N, Pickering-Brown S, Adamson J, Lees AJ, Rossor MN, Quinn NP, Kertesz A, Khan MN, Hardy J, Lantos PL, St George-Hyslop P, Munoz DG, Mann D, Lang AE, Bergeron C, Bigio EH, Litvan I, Bhatia KP, Dickson D, Wood NW, Hutton M: Corticobasal degeneration and progressive supranuclear palsy share a common tau haplotype. Neurology 2001, 56:1702-1706.

53. Boeve BF, Maraganore DM, Parisi JE, Ivnik RJ, Westmoreland BF, Dickson DW, Hutton M, Hardy J, Caselli RJ, Petersen RC: Corticobasal degeneration and frontotemporal dementia presentations in a kindred with nonspecific histopathology. Dement Geriatr Cogn Disord 2002, 13:80-90.

54. Brown J, Lantos PL, Roques P, Fidani L, Rossor MN: Familial dementia with swollen achromatic neurons and corticobasal inclusion bodies: a clinical and pathological study. J Neuro/ Sci 1996, 135:21-30.

55. Brown J, Lantos PL, Rossor MN: Familial dementia lacking specific pathological features presenting with clinical features of corticobasal degeneration. J Neurol Neurosurg Psychiatry 1998, 65:600-603.

56. Bugiani O, Murrell JR, Giaccone G, Hasegawa M, Ghigo G, Tabaton M, Morbin M, Primavera A, Carella F, Solaro C, Grisoli M, Savoiardo M, Spillantini MG Tagliavini F, Goedert M, Ghetti B: Frontotemporal dementia and corticobasal degeneration in a family with a P301S mutation in tau. J Neuropathol Exp Neurol 1999, 58:667-677.

57. Gallien P, Verin M, Rancurel G, De Marco O, Eden G: First familial cases of corticobasal degeneration. Neurology 1998, 50:A428.

58. Casseron W, Azulay JP, Guedj E, Gastaut JL, Pouget J: Familial autosomal dominant cortico-basal degeneration with the P301S mutation in the tau gene: an example of phenotype variability. J Neurol 2005, 252:1546-1548.

59. Tuite PJ, Clark HB, Bergeron C, Bower M, St George-Hyslop P, Mateva V, Anderson J, Knopman DS: Clinical and pathologic evidence of corticobasal degeneration and progressive supranuclear palsy in familial tauopathy. Arch Neurol 2005, 62:1453-1457.

60. Uchihara T, Nakayama H: Familial tauopathy mimicking corticobasal degeneration an autopsy study on three siblings. J Neurol Sci 2006 246:45-51.

61. Emre M, Aarsland D, Brown R, Burn DJ, Duyckaerts C, Mizuno Y, Broe GA Cummings J, Dickson DW, Gauthier S, Goldman J, Goetz C, Korczyn A, Lees A, Levy R, Litvan I, McKeith I, Olanow W, Poewe W, Quinn N, Sampaio C, Tolosa E, Dubois B: Clinical diagnostic criteria for dementia associated with Parkinson's disease. Mov Disord 2007, 22:1689-1707.

62. McKeith I, Mintzer J, Aarsland D, Burn D, Chiu H, Cohen-Mansfield J, Dickson D, Dubois B, Duda JE, Feldman H, Gauthier S, Halliday G, Lawlor B, Lippa C, Lopez OL, Carlos Machado J, O'Brien J, Playfer J, Reid W: Dementia with Lewy bodies. Lancet Neurol 2004, 3:19-28.

63. Kehagia AA, Barker RA, Robbins TW: Neuropsychological and clinical heterogeneity of cognitive impairment and dementia in patients with Parkinson's disease. Lancet Neuro/ 2010, 9:1200-1213.

64. Lang AE, Lozano AM: Parkinson's disease. First of two parts. N Engl J Med
1998, 339:1044-1053

65. Compta Y, Parkkinen L, O'Sullivan SS, Vandrovcova J, Holton JL, Collins C, Lashley T, Kallis C, Williams DR, de SR, Lees AJ, Revesz T: Lewy- and Alzheimer-type pathologies in Parkinson's disease dementia: which is more important? Brain 2011, 134:1493-1505.

66. Irwin DJ, White MT, Toledo JB, Xie SX, Robinson JL, Van D, V, Lee VM, Leverenz JB, Montine TJ, Duda JE, Hurtig HI, Trojanowski JQ: Neuropathologic substrates of Parkinson disease dementia. Ann Neurol 2012, 72:587-598.

67. Jellinger KA, Attems J: Prevalence and impact of vascular and Alzheimer pathologies in Lewy body disease. Acta Neuropathol 2008, 115:427-436.

68. Tsuboi Y, Uchikado H, Dickson DW: Neuropathology of Parkinson's disease dementia and dementia with Lewy bodies with reference to striatal pathology. Parkinsonism Relat Disord 2007, 13(Suppl 3):S221-S224.

69. Williams-Gray CH, Evans JR, Goris A, Foltynie T, Ban M, Robbins TW, Brayne C, Kolachana BS, Weinberger DR, Sawcer SJ, Barker RA: The distinct cognitive syndromes of Parkinson's disease: 5 year follow-up of the CamPalGN cohort. Brain 2009, 132:2958-2969.

70. Morley JF, Xie SX, Hurtig HI, Stern MB, Colcher A, Horn S, Dahodwala N, Duda JE, Weintraub D, Chen-Plotkin AS, Van D, V, Falcone D, Siderowf A: Genetic influences on cognitive decline in Parkinson's disease. Mov Disord 2012, 27:512-518.

71. Tsuang D, Leverenz JB, Lopez L, Hamilton RL, Bennett D, Schneider JA Buchman AS, Larson EB, Crane PK, Kaye J, Kramer P, Woltjer R, Trojanowski JQ Weintraub D, Chen-Plotkin AS, Irwin DJ, Rick J, Schellenberg GD, Watson S, Kukull W, Nelson PT, Jicha G, Neltner JH, Galasko D, Masliah E, Quinn JF, Chung KA, Yearout D, Mata IF, Wan JY, et al:: APOE E4 increases risk for dementia in pure synucleinopathies. JAMA Neurol 2012, 70:223-228.

72. Waters $\mathrm{CH}$, Miller CA: Autosomal dominant Lewy body parkinsonism in a four-generation family. Ann Neurol 1994, 35:59-64.

73. Golbe LI, Di IG, Bonavita V, Miller DC, Duvoisin RC: A large kindred with autosomal dominant Parkinson's disease. Ann Neurol 1990, 27:276-282.

74. Meeus B, Theuns J, Van BC: The genetics of dementia with lewy bodies: what are we missing? Arch Neurol 2012,69:1113-1118.

75. Ishikawa A, Piao YS, Miyashita A, Kuwano R, Onodera O, Ohtake H, Suzuki M, Nishizawa M, Takahashi H: A mutant PSEN1 causes dementia with Lewy bodies and variant Alzheimer's disease. Ann Neurol 2005, 57:429-434

76. Piscopo P, Marcon G, Piras MR, Crestini A, Campeggi LM, Deiana E, Cherchi R, Tanda F, Deplano A, Vanacore N, Tagliavini F, Pocchiari M, Giaccone G, Confaloni A: A novel PSEN2 mutation associated with a peculiar phenotype. Neurology 2008, 70:1549-1554.

77. Rosenberg CK, Pericak-Vance MA, Saunders AM, Gilbert JR, Gaskell PC, Hulette CM: Lewy body and Alzheimer pathology in a family with the amyloidbeta precursor protein APP717 gene mutation. Acta Neuropathol 2000, 100:145-152

78. Snider BJ, Norton J, Coats MA, Chakraverty S, Hou CE, Jervis R, Lendon CL, Goate AM, MCKeel DW, Jr, Morris JC: Novel presenilin 1 mutation (S170F) causing Alzheimer disease with Lewy bodies in the third decade of life. Arch Neurol 2005, 62:1821-1830

79. Clark LN, Kartsaklis LA, Wolf GR, Dorado B, Ross BM, Kisselev S, Verbitsky M, Mejia-Santana H, Cote L, Andrews H, Vonsattel JP, Fahn S, Mayeux R, Honig LS, Marder K: Association of glucocerebrosidase mutations with dementia with lewy bodies. Arch Neurol 2009, 66:578-583.

80. Nishioka K, Ross OA, Vilarino-Guell C, Cobb SA, Kachergus JM, Mann DM, Snowden J, Richardson AM, Neary D, Robinson CA, Rajput A, Papapetropoulos S, Mash DC, Pahwa R, Lyons KE, Wszolek ZK, Dickson DW Farrer MJ: Glucocerebrosidase mutations in diffuse Lewy body disease. Parkinsonism Relat Disord 2011, 17:55-57.

81. Tsuang D, Leverenz JB, Lopez OL, Hamilton RL, Bennett DA, Schneider JA, Buchman AS, Larson EB, Crane PK, Kaye JA, Kramer P, Woltjer R, Kukull W, Nelson PT, Jicha GA, Neltner JH, Galasko D, Masliah E, Trojanowski JO. Schellenberg GD, Yearout D, Huston H, Fritts-Penniman A, Mata IF, Wan JY, Edwards KL, Montine TJ, Zabetian CP: GBA mutations increase risk for Lewy body disease with and without Alzheimer disease pathology. Neurology 2012, 79:1944-1950.

82. Nalls MA, Duran R, Lopez G, Kurzawa-Akanbi M, McKeith IG, Chinnery PF, Morris CM, Theuns J, Crosiers D, Cras P, Engelborghs S, De Deyn PP, Van Broeckhoven C, Mann DM, Snowden J, Pickering-Brown S, Halliwell N, Davidson Y, Gibbons L, Harris J, Sheerin UM, Bras J, Hardy J, Clark L, Marder K, Honig LS, Berg D, Maetzler W, Brockmann K, Gasser T, et al: A multicenter study of glucocerebrosidase mutations in dementia with Lewy bodies. JAMA Neurol 2013, 70:727-735. 
83. Cullen V, Sardi SP, Ng J, Xu YH, Sun Y, Tomlinson JJ, Kolodziej P, Kahn I, Saftig P Woulfe J, Rochet JC, Glicksman MA, Cheng SH, Grabowski GA, Shihabuddin LS, Schlossmacher MG: Acid beta-glucosidase mutants linked to Gaucher disease, Parkinson disease, and Lewy body dementia alter alpha-synuclein processing. Ann Neurol 2011, 69:940-953.

84. Black SE: Vascular cognitive impairment: epidemiology, subtypes, diagnosis and management. J R Coll Physicians Edinb 2011, 41:49-56.

85. Honjo K, Black SE, Verhoeff NP: Alzheimer's disease, cerebrovascular disease, and the beta-amyloid cascade. Can J Neurol Sci 2012, 39:712-728.

86. Knopman D, Boland LL, Mosley T, Howard G, Liao D, Szklo M, McGovern P, Folsom AR: Cardiovascular risk factors and cognitive decline in middleaged adults. Neurology 2001, 56:42-48.

87. Behl P, Bocti C, Swartz RH, Gao F, Sahlas DJ, Lanctot KL, Streiner DL, Black SE: Strategic subcortical hyperintensities in cholinergic pathways and executive function decline in treated Alzheimer patients. Arch Neuro/ 2007, 64:266-272.

88. Swartz RH, Sahlas DJ, Black SE: Strategic involvement of cholinergic pathways and executive dysfunction: does location of white matter signal hyperintensities matter? J Stroke Cerebrovasc Dis 2003, 12:29-36.

89. Swartz RH, Stuss DT, Gao F, Black SE: Independent cognitive effects of atrophy and diffuse subcortical and thalamico-cortical cerebrovascular disease in dementia. Stroke 2008, 39:822-830.

90. Moorhouse P, Rockwood K: Vascular cognitive impairment: current concepts and clinical developments. Lancet Neurol 2008, 7:246-255.

91. O'Brien JT, Erkinjuntti T, Reisberg B, Roman G, Sawada T, Pantoni L, Bowler JV, Ballard C, DeCarli C, Gorelick PB, Rockwood K, Burns A, Gauthier S, Dekosky ST: Vascular cognitive impairment. Lancet Neurol 2003, 2:89-98.

92. Ferro JM, Massaro AR, Mas JL: Aetiological diagnosis of ischaemic stroke in young adults. Lancet Neurol 2010, 9:1085-1096.

93. Chabriat H, Joutel A, Dichgans M, Tournier-Lasserve E, Bousser MG: Cadasil. Lancet Neurol 2009, 8:643-653.

94. Hajj-Ali RA, Singhal AB, Benseler S, Molloy E, Calabrese LH: Primary angiitis of the CNS. Lancet Neurol 2011, 10:561-572.

95. Duna GF, Calabrese LH: Limitations of invasive modalities in the diagnosis of primary angiitis of the central nervous system. J Rheumatol 1995, 22:662-667.

96. Eng JA, Frosch MP, Choi K, Rebeck GW, Greenberg SM: Clinical manifestations of cerebral amyloid angiopathy-related inflammation. Ann Neurol 2004, 55:250-256

97. Cabrejo L, Guyant-Marechal L, Laquerriere A, Vercelletto M, De la Fourniere F, Thomas-Anterion C, Verny C, Letournel F, Pasquier F, Vital A, Checler F, Frebourg T, Campion D, Hannequin D: Phenotype associated with APP duplication in five families. Brain 2006, 129:2966-2976.

98. Hsiung GY: Inherited metabolic dementias. In Other Dementias. Edited by David Geldmacher. Delray Beach FL: Carma Publishing; 2008:95-122.

99. Fadil H, Borazanci A, it Ben HE, Yahyaoui M, Korniychuk E, Jaffe SL, Minagar A Early onset dementia. Int Rev Neurobio/ 2009, 84:245-262.

100. Vincent A, Bien CG, Irani SR, Waters P: Autoantibodies associated with diseases of the CNS: new developments and future challenges. Lancet Neurol 2011, 10:759-772

101. Warren JD, Schott JM, Fox NC, Thom M, Revesz T, Holton JL, Scaravilli F, Thomas DG, Plant GT, Rudge P, Rossor MN: Brain biopsy in dementia. Brain 2005, 128:2016-2025.

102. Geschwind MD, Shu H, Haman A, Sejvar JJ, Miller BL: Rapidly progressive dementia. Ann Neurol 2008, 64:97-108.

103. McKhann GM, Knopman DS, Chertkow H, Hyman BT, Jack CR, Jr, Kawas CH, Klunk WE, Koroshetz WJ, Manly JJ, Mayeux R, Mohs RC, Morris JC, Rossor MN, Scheltens P, Carrillo MC, Thies B, Weintraub S, Phelps CH: The diagnosis of dementia due to Alzheimer's disease: recommendations from the National Institute on Aging-Alzheimer's Association workgroups on diagnostic guidelines for Alzheimer's disease. Alzheimers Dement 2011, 7:263-269.

104. Sullivan EV, Pfefferbaum A: Neuroimaging of the Wernicke-Korsakoff syndrome. Alcohol Alcohol 2009, 44:155-165.

105. Bell B, Lin JJ, Seidenberg M, Hermann B: The neurobiology of cognitive disorders in temporal lobe epilepsy. Nat Rev Neurol 2011, 7:154-164.

106. Sadler RM: The syndrome of mesial temporal lobe epilepsy with hippocampal sclerosis: clinical features and differential diagnosis. Adv Neurol 2006, 97:27-37.

107. Gultekin SH, Rosenfeld MR, Voltz R, Eichen J, Posner JB, Dalmau J: Paraneoplastic limbic encephalitis: neurological symptoms, immunological findings and tumour association in 50 patients. Brain 2000 123(Pt 7):1481-1494

108. Voltz R: Paraneoplastic neurological syndromes: an update on diagnosis, pathogenesis, and therapy. Lancet Neurol 2002, 1:294-305.

109. Sorbi S, Hort J, Erkinjuntti T, Fladby T, Gainotti G, Gurvit H, Nacmias B, Pasquier F, Popescu BO, Rektorova I, Religa D, Rusina R, Rossor M, Schmidt R, Stefanova E, Warren JD, Scheltens P: EFNS-ENS guidelines on the diagnosis and management of disorders associated with dementia. Eur J Neurol 2012, 19:1159-1179.

110. Josephs KA, Duffy JR: Apraxia of speech and nonfluent aphasia: a new clinical marker for corticobasal degeneration and progressive supranuclear palsy. Curr Opin Neurol 2008, 21:688-692.

111. Snowden JS, Pickering-Brown SM, Mackenzie IR, Richardson AM, Varma A, Neary D, Mann DM: Progranulin gene mutations associated with frontotemporal dementia and progressive non-fluent aphasia. Brain 2006 129:3091-3102.

112. Pickering-Brown SM, Rollinson S, Du PD, Morrison KE, Varma A, Richardson AM, Neary D, Snowden JS, Mann DM: Frequency and clinical characteristics of progranulin mutation carriers in the Manchester frontotemporal lobar degeneration cohort: comparison with patients with MAPT and no known mutations. Brain 2008, 131:721-731.

113. Cohn-Hokke PE, Elting MW, Pijnenburg YA, van Swieten JC: Genetics of dementia: update and guidelines for the clinician. Am J Med Genet $B$ Neuropsychiatr Genet 2012, 159B:628-643.

114. Khan BK, Yokoyama JS, Takada LT, Sha SJ, Rutherford NJ, Fong JC, Karydas AM, Wu T, Ketelle RS, Baker MC, Hernandez MD, Coppola G, Geschwind DH, Rademakers R, Lee SE, Rosen HJ, Rabinovici GD, Seeley WW, Rankin KP, Boxer AL, Miller BL: Atypical, slowly progressive behavioural variant frontotemporal dementia associated with C9ORF72 hexanucleotide expansion. J Neurol Neurosurg Psychiatry 2012, 83:358-364.

115. Snowden JS, Rollinson S, Thompson JC, Harris JM, Stopford CL, Richardson AM, Jones M, Gerhard A, Davidson YS, Robinson A, Gibbons L, Hu Q, DuPlessis D, Neary D, Mann DM, Pickering-Brown SM: Distinct clinical and pathological characteristics of frontotemporal dementia associated with C9ORF72 mutations. Brain 2012, 135:693-708.

116. Whitwell JL, Weigand SD, Boeve BF, Senjem ML, Gunter JL, DeJesusHernandez M, Rutherford NJ, Baker M, Knopman DS, Wszolek ZK, Parisi JE, Dickson DW, Petersen RC, Rademakers $R$, Jack CR, Jr, Josephs KA: Neuroimaging signatures of frontotemporal dementia genetics: C9ORF72, tau, progranulin and sporadics. Brain 2012, 135:794-806.

117. Testai FD, Gorelick PB: Inherited metabolic disorders and stroke part 1 : Fabry disease and mitochondrial myopathy, encephalopathy, lactic acidosis, and strokelike episodes. Arch Neurol 2010, 67:19-24.

118. Walker Z, Jaros E, Walker RW, Lee L, Costa DC, Livingston G, Ince PG, Perry R, McKeith I, Katona CL: Dementia with Lewy bodies: a comparison of clinical diagnosis, FP-CIT single photon emission computed tomography imaging and autopsy. J Neurol Neurosurg Psychiatry 2007, 78:1176-1181.

119. Sevin M, Lesca G, Baumann N, Millat G, Lyon-Caen O, Vanier MT, Sedel F: The adult form of Niemann-Pick disease type C. Brain 2007, 130:120-133.

120. Brewer GJ, Fink JK, Hedera P: Diagnosis and treatment of Wilson's disease. Semin Neurol 1999, 19:261-270.

121. Crutch SJ, Lehmann M, Schott JM, Rabinovici GD, Rossor MN, Fox NC: Posterior cortical atrophy. Lancet Neurol 2012, 11:170-178.

122. Kas A, de Souza LC, Samri D, Bartolomeo P, Lacomblez L, Kalafat M, Migliaccio $\mathrm{R}$, Thiebaut de SM, Cohen L, Dubois B, Habert MO, Sarazin M: Neural correlates of cognitive impairment in posterior cortical atrophy. Brain 2011, 134:1464-1478

123. Tang-Wai DF, Graff-Radford NR, Boeve BF, Dickson DW, Parisi JE, Crook R, Caselli RJ, Knopman DS, Petersen RC: Clinical, genetic, and neuropathologic characteristics of posterior cortical atrophy. Neurology 2004, 63:1168-1174.

124. Charrow J, Andersson HC, Kaplan P, Kolodny EH, Mistry P, Pastores G, Rosenbloom BE, Scott CR, Wappner RS, Weinreb NJ, Zimran A: The Gaucher registry: demographics and disease characteristics of 1698 patients with Gaucher disease. Arch Intern Med 2000, 160:2835-2843.

125. Berry-Kravis E, Abrams L, Coffey SM, Hall DA, Greco C, Gane LW, Grigsby J, Bourgeois JA, Finucane B, Jacquemont S, Brunberg JA, Zhang L, Lin J, Tassone F, Hagerman PJ, Hagerman RJ, Leehey MA: Fragile X-associated tremor/ ataxia syndrome: clinical features, genetics, and testing guidelines. Mov Disord 2007, 22:2018-2030.

126. Frey LC, Ringel SP, Filley CM: The natural history of cognitive dysfunction in late-onset GM2 gangliosidosis. Arch Neurol 2005, 62:989-994. 
127. Rademakers R, Baker M, Nicholson AM, Rutherford NJ, Finch N, Soto-Ortolaza A, Lash J, Wider C, Wojtas A, DeJesus-Hernandez M, Adamson J, Kouri N, Sundal C, Shuster EA, Aasly J, MacKenzie J, Roeber S, Kretzschmar HA, Boeve BF, Knopman DS, Petersen RC, Cairns NJ, Ghetti B, Spina S, Garbern J, Tselis AC, Uitti R, Das P, Van Gerpen JA, Meschia JF, et al: Mutations in the colony stimulating factor 1 receptor (CSF1R) gene cause hereditary diffuse leukoencephalopathy with spheroids. Nat Genet 2012, 44:200-205.

128. Berkovic SF, Carpenter S, Andermann F, Andermann E, Wolfe LS: Kufs' disease: a critical reappraisal. Brain 1988, 111(Pt 1):27-62

129. Tsuji S: Dentatorubral-pallidoluysian atrophy. Handb Clin Neurol 2012, 103:587-594.

130. Gallus GN, Dotti MT, Federico A: Clinical and molecular diagnosis of cerebrotendinous xanthomatosis with a review of the mutations in the CYP27A1 gene. Neurol Sci 2006, 27:143-149.

131. Engelen M, Kemp S, de VM, van Geel BM, Wanders RJ, Aubourg P; Poll-The BT: X-linked adrenoleukodystrophy (X-ALD): clinical presentation and guidelines for diagnosis, follow-up and management. Orphanet J Rare Dis 2012, 7:51.

132. Kohler W: Leukodystrophies with late disease onset: an update. Curr Opin Neurol 2010, 23:234-241.

133. Durr A: Autosomal dominant cerebellar ataxias: polyglutamine expansions and beyond. Lancet Neurol 2010, 9:885-894.

134. Hartig MB, Prokisch $H$, Meitinger T, Klopstock T: Pantothenate kinaseassociated neurodegeneration. Curr Drug Targets 2012, 13:1 182-1189.

135. Walker FO: Huntington's disease. Lancet 2007, 369:218-228.

doi:10.1186/alzrt197

Cite this article as: Masellis M, et al: Early-onset dementias: diagnostic and etiological considerations. Alzheimer's Research \& Therapy 2013, 5(Suppl 1):S7. 